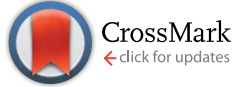

Cite this: RSC Adv., 2015, 5, 28582

Received 23rd February 2015 Accepted 16th March 2015

DOI: $10.1039 / \mathrm{c} 5 \mathrm{ra03321g}$

www.rsc.org/advances

\section{Synthesis of norbornane bisether antibiotics via silver-mediated alkylation $\uparrow$}

Shane M. Hickey, ${ }^{a}$ Trent D. Ashton, ${ }^{a}$ Jonathan M. White, ${ }^{b}$ Jian Li, ${ }^{c}$ Roger L. Nation, ${ }^{c}$ Heidi Y. Yu, ${ }^{c}$ Alysha G. Elliott, ${ }^{d}$ Mark S. Butler, ${ }^{d}$ Johnny X. Huang, ${ }^{d}$ Matthew A. Cooper ${ }^{d}$ and Frederick M. Pfeffer ${ }^{\star a}$

A small series of norbornane bisether diguanidines have been synthesized and evaluated as antibacterial agents. The key transformation-bisalkylation of norbornane diol 6-was not successful using Williamson methodology but has been accomplished using $\mathrm{Ag}_{2} \mathrm{O}$ mediated alkylation. Further functionalization to incorporate two guanidinium groups gave rise to a series of structurally rigid cationic amphiphiles; several of which (16d, $16 \mathrm{~g}$ and $16 \mathrm{~h}$ ) exhibited antibiotic activity. For example, compound $16 \mathrm{~d}$ was active against a broad range of bacteria including Pseudomonas aeruginosa ( $\left.\mathrm{MIC}=8 \mu \mathrm{g} \mathrm{mL}^{-1}\right)$, Escherichia coli $\left(\mathrm{MIC}=8 \mu \mathrm{g} \mathrm{mL}^{-1}\right)$ and methicillin-resistant Staphylococcus aureus $\left(\mathrm{MIC}=8 \mu \mathrm{g} \mathrm{mL}^{-1}\right)$.

\section{Introduction}

Antibacterial resistance is now a global medical concern. ${ }^{1-4}$ A decline in the number of pharmaceutical companies pursuing new therapeutics, and the continued misuse of antibiotics has only served to exacerbate the problem..$^{1-5}$ Many antibacterial agents that target the lipopolysaccharide (LPS) layer of Gramnegative bacteria either possess or adopt an amphiphilic structure. ${ }^{6-10}$ It has also been shown that appropriate functionalization of a rigidified core (such as a calixarene) enables facially amphiphilic compounds to be constructed. ${ }^{7-11}$ The bicyclo[2.2.1]heptane (norbornane) scaffold represents one of the most accessible, preorganized frameworks available and has a history of use in many fields of chemistry. Biologically active examples include: naxifylline 1 (an $\mathrm{A}_{1}$-adenosine receptor antagonist), ${ }^{12} \mathrm{~N}^{6}$ (5,6-epoxynorbornyl)adenonsines $\left(\mathrm{A}_{1}\right.$-adenosine receptor agonists) ${ }^{13-15}$ and diguanidine 3, (active against Gram-negative bacteria). ${ }^{\mathbf{1 6}}$ In supramolecular chemistry norbornanes have found use in organogel formation, ${ }^{\mathbf{1 7}}$ whilst fused polynorbornanes have been successfully employed as scaffolds for

${ }^{a}$ Research Centre for Chemistry and Biotechnology, School of Life and Environmental Sciences, Deakin University, Waurn Ponds, Victoria, 3216, Australia. E-mail: fred. pfeffer@deakin.edu.au

${ }^{b}$ Bio21 Institute, School of Chemistry, University of Melbourne, Parkville, Victoria, 3010, Australia

${ }^{c}$ Drug Delivery, Disposition and Dynamics, Monash Institute of Pharmaceutical Science, Royal Parade, Parkville, Victoria, 3052, Australia

${ }^{d}$ Institute for Molecular Bioscience, The University of Queensland, Brisbane, Queensland, 4072, Australia

$\dagger$ Electronic supplementary information (ESI) available: Crystal structure of compound 12h (CIF), synthetic procedures for all previously reported compounds and copies of NMR spectra $\left({ }^{1} \mathrm{H},{ }^{13} \mathrm{C},{ }^{19} \mathrm{~F}\right)$ for all new compounds. CCDC 1050585. For ESI and crystallographic data in CIF or other electronic format see DOI: 10.1039/c5ra03321g both anion recognition, ${ }^{18-21}$ and as ligands for the construction of metal-organic cages. ${ }^{22}$ In the field of asymmetric synthesis, chiral auxiliaries (such as 2) based on the norbornane framework have also been successfully employed. ${ }^{23,24}$

It is known that ethers typically demonstrate better in vivo stability than acetals, ${ }^{25}$ therefore, analogs of antibacterial $3^{\mathbf{1 6}}$ (Fig. 1) that followed the general structure 4 (Scheme 1) were considered attractive targets. In order to construct this class of compounds it was envisaged that bisether diacids (5) would be useful building blocks and these could in turn be synthesized from norbornane diol 6 (Scheme 1).

The direct alkylation of norbornane diol $\mathbf{6}$ is as yet unreported in the literature, which is presumably because the reaction is troublesome. Indeed, it has been shown that in some cases alkylation of alcohols using typical Williamson protocols gives lower than expected yields, or no desired product. ${ }^{26,27}$ Indeed, in circumstances where a stabilized leaving group can be formed the basic conditions employed can lead to an elimination/fragmentation event. ${ }^{28,29}$ An example of this competitive elimination was described by Hergueta et al. (Scheme 2); alkoxide 7, derived from a norbornane fused to a quinoxaline, undergoes elimination to give a carbanion (8) which is stabilized by the aromatic heterocyclic. ${ }^{30}$

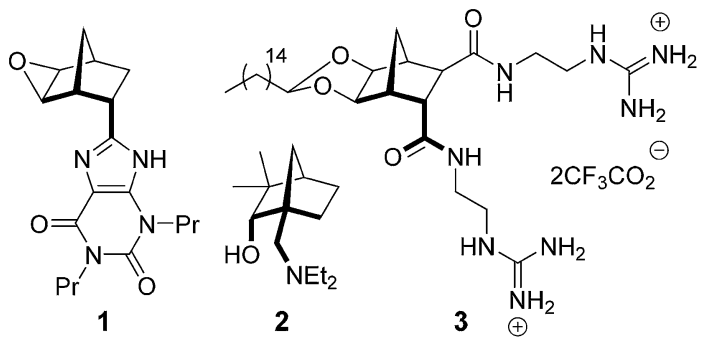

Fig. 1 Examples of functionalized norbornanes. 
<smiles>[R]O[C@H]1C[C@H]2C[C@@H](C1C(=O)NCCNC(N)=[NH2+])[C@H](C(=O)NCCNC(N)=[NH2+])[C@H]2O[R]</smiles><smiles>C=CC</smiles>
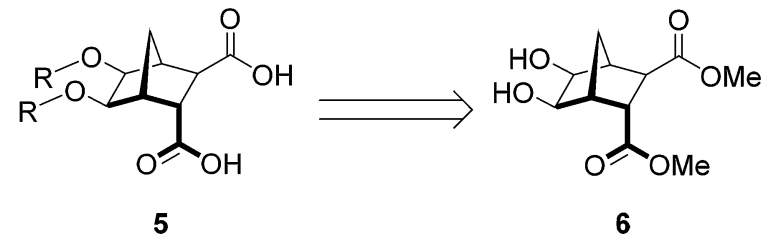

Scheme 1 Access to bisether diguanidine 4 from diol 6 .

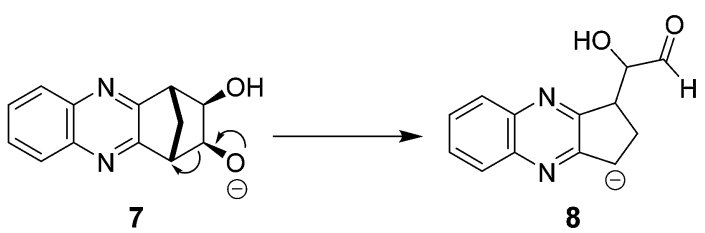

Scheme 2 Ring opening to give stabilized 'benzylic' carbanion as observed by Hergueta et al. ${ }^{30}$

The use of silver(I) oxide for the transformation of an alcohol to a methyl ether has been known for well over a century. ${ }^{31}$ The Irvine-Purdie method has been used to achieve (i) mono-

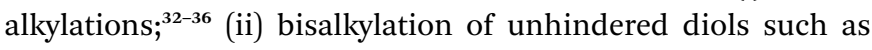
cycohexanediol; ${ }^{37}$ and (iii) per-methylation of carbohydrates such as glucose, galactose and fructose..$^{31,38}$ Inefficient reaction conditions (e.g. multiple additions of the alkylating agent ${ }^{34}$ or carrying the reaction out in neat alkylating agent) means the Irvine-Purdie alkylation is often overlooked in favour of Williamson methodology. To the best of our knowledge, the use of silver(I) oxide for the bisalkylation of eclipsed syn-1,2-diols has not been previously described.

Herein, we report a protocol for the bisalkylation of the sterically hindered 1,2-diol 6 using silver(I) oxide and a small excess (4.6 equiv.) of suitable alkyl halides. Hydrolysis of the esters gave access to compounds of the general structure 5, which were shown to exist in a sterically congested environment around the two alkyl groups by X-ray crystallography. Subsequent functionalization afforded a series of diguanidines (4, Scheme 1), that were tested against a range of Gram-negative and Gram-positive bacteria (Tables 3 and 4).

\section{Results \& discussion}

\section{Chemistry}

The starting diester diol 6 was synthesized in two steps from dimethyl fumarate. ${ }^{16,39}$ The norbornane framework was constructed using either standard Diels-Alder conditions (99\%) or by a solvent-free, microwave-assisted approach ( 2 hours at $150{ }^{\circ} \mathrm{C}, 98 \%$ ) similar to that reported by Nencka and co-workers. ${ }^{39}$ The syn-1,2-diol 6 was synthesized in excellent yields $(94 \%)$ on multigram scales (up to $4 \mathrm{~g}$ ), using $\mathrm{OsO}_{4}(0.1$ mol\%) mediated dihydroxylation of the norbornene using 4methylmorpholine $N$-oxide (NMO) as a co-oxidant. ${ }^{16,40}$ Dihydroxylation using $\mathrm{KMnO}_{4}$, as detailed by Donohoe, ${ }^{41}$ was also successful, albeit in lower yield (58\%) (see ESI† for full reaction conditions).

Williamson methodology was initially trialled using $6, \mathrm{NaH}$, MeI, at $55{ }^{\circ} \mathrm{C}$ (Scheme 2) and after 16 hours the diol had been completely consumed (as determined by TLC analysis). However, examination of the crude product using ${ }^{1} \mathrm{H}$ NMR spectroscopy showed no signs of the desired bisether 9a. Instead, a complex mixture (inseparable by column chromatography) was produced. Deprotonation with $n$-BuLi in THF at -78 to $0{ }^{\circ} \mathrm{C}$ was also trialled but again the reaction was unsuccessful. Given that similar norbornane diols undergo base-induced ring opening to give stabilized anions (Scheme 2),,$^{30}$ we propose that following deprotonation, a Grob-type fragmentation occurs to give a stabilized enolate (11, Scheme 3). ${ }^{42}$

The Sakai group have described the reduction of esters to the corresponding ethers using $\mathrm{Et}_{3} \mathrm{SiH}$ in the presence of catalytic $\mathrm{InBr}_{3}{ }^{43}$ Unfortunately, in the current work, after acetylation of diol 6 to form diacetate 20 (63\%, see Experimental section), ${ }^{41}$ reaction with $\mathrm{InBr}_{3}$ failed to produce the bisether product; instead ${ }^{1} \mathrm{H}$ NMR analysis indicated that a complex mixture of products had formed.

In light of these failures, attention turned towards the use of $\mathrm{Ag}_{2} \mathrm{O}^{32-37,44,45}$ Indeed, when diol 6 was reacted with $\mathrm{Ag}_{2} \mathrm{O}$ (1.6 equiv.) and MeI (4.6 equiv.) in DMF at ambient temperature for 48 hours (Scheme 4), bisether 9a was isolated in good yield $(67 \%){ }^{33}$ Saponification of diester 9a gave the required bisether diacid (12a) in 73\% yield (Scheme 4). Extended reaction times, adding further portions of MeI throughout the reaction, and heating the reaction (both conventional and microwave irradiation), did not lead to increased yields. Using $\mathrm{Ag}_{2} \mathrm{CO}_{3}, \mathrm{AgNO}_{3}$, $\mathrm{AgBF}_{4}$ or $\mathrm{AgPF}_{6}$ gave none of the desired product with only starting material recovered.
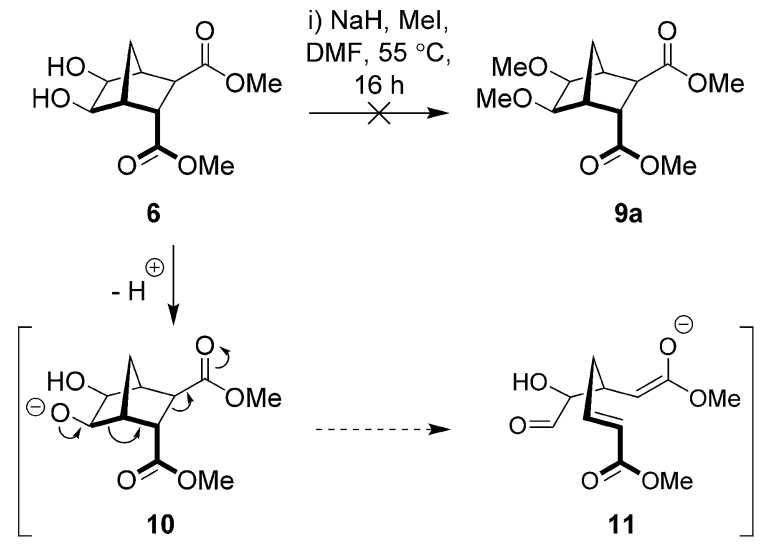

Scheme 3 Failed attempt to access bisether 9a and the possible pathway leading to enolate 11 . 


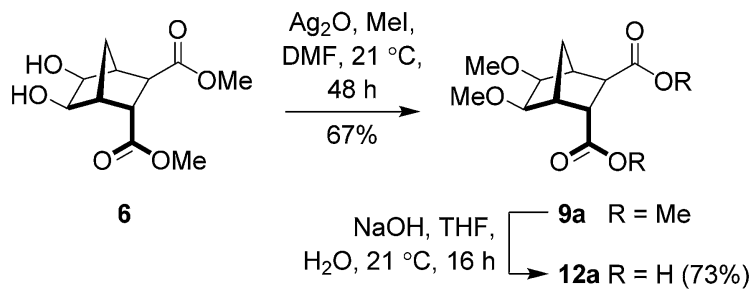

Scheme 4 Synthesis of diacid 12a.

To further test the scope of these reaction conditions a range of benzyl halides were used. Using benzyl bromide (Table 1, entry 2), bisether diacid 12b was attained over two steps $(18 \%$ using $300 \mathrm{mg}$ of 6). Pleasingly, when the reaction was performed on a larger scale (900 $\mathrm{mg}$ of 6 ), the yield increased to $37 \%$. A Finkelstein approach ${ }^{46}$ using NaI did not increase the yield of bisether diacid $\mathbf{1 2 b}$. The low yields can be rationalized somewhat by the steric bulk introduced as a result of the first benzylation-the reaction with the second equivalent of benzyl halide is considerably inhibited. Indeed, an appreciable amount of the monoalkylated regioisomer (37\%) was isolated along with the desired bisether product 12b. Similarly, using 2methylbenzyl bromide, 12c was accessed in 19\% yield (Table 1, entry 3), and a reasonable quantity of a monoalkylated intermediate was also isolated (39\%). Despite the modest yields, this protocol provided access to the desired norbornane bisethersa previously inaccessible family of compounds.

When a range of fluorinated benzyl bromides were used good yields of the desired bisether products were obtained. Following the aforementioned two-step process, 12d (51\%) and 12e (55\%) were accessed using 4-(trifluoromethyl)benzyl bromide and 3-fluorobenzyl bromide respectively (Table 1, entries 4 and 5). Furthermore, when 4-fluorobenzyl bromide was employed to alkylate diol $\mathbf{6}$, and following hydrolysis of the ester groups using $\mathrm{NaOH} / \mathrm{THF}$ (Table 1, entry 6) diacid 12f was obtained in moderate yield (25\%) over the two steps.

Using 3-bromobenzyl bromide and 4-bromobenzyl bromide the synthesis of bisether diacids $\mathbf{1 2 g}$ and $\mathbf{1 2 h}$ (24 and 28\% over two steps respectively, Table 1, entries 7 and 8) was carried out in the same fashion. Crystals suitable for X-ray diffraction were obtained for bisether diacid $\mathbf{1 2 h}$ after recrystallization from EtOH/pet. spirits. The resulting structure contained a unit cell comprised of two conformational isomers (as shown in Fig. 2). The $\mathrm{O} \cdots \mathrm{O}$ distance ( $c a .2 .6 \AA$ ), clearly illustrates the proximity of the two benzyl groups and their non-symmetric orientation (presumably due to steric constraints).

When allyl bromide was used, stirring for 4 days was required to consume all the starting material; subsequent ester hydrolysis gave diacid $12 \mathrm{i}$ in a $25 \%$ yield over the two steps (Table 1, entry 9). Unfortunately, reactions with 4-methoxybenzyl chloride and 4-nitrobenzyl bromide (Table 1, entries 10 and 11) failed to give any of the desired product with only minimal consumption of starting material taking place (as evidenced by ${ }^{1} \mathrm{H}$ NMR analysis of the crude reaction mixture). Also, when 1-iodooctane (Table 1, entry 12) was employed alkylation was unsuccessful.
Table 1 Synthesis of bisether diacids 12a-i

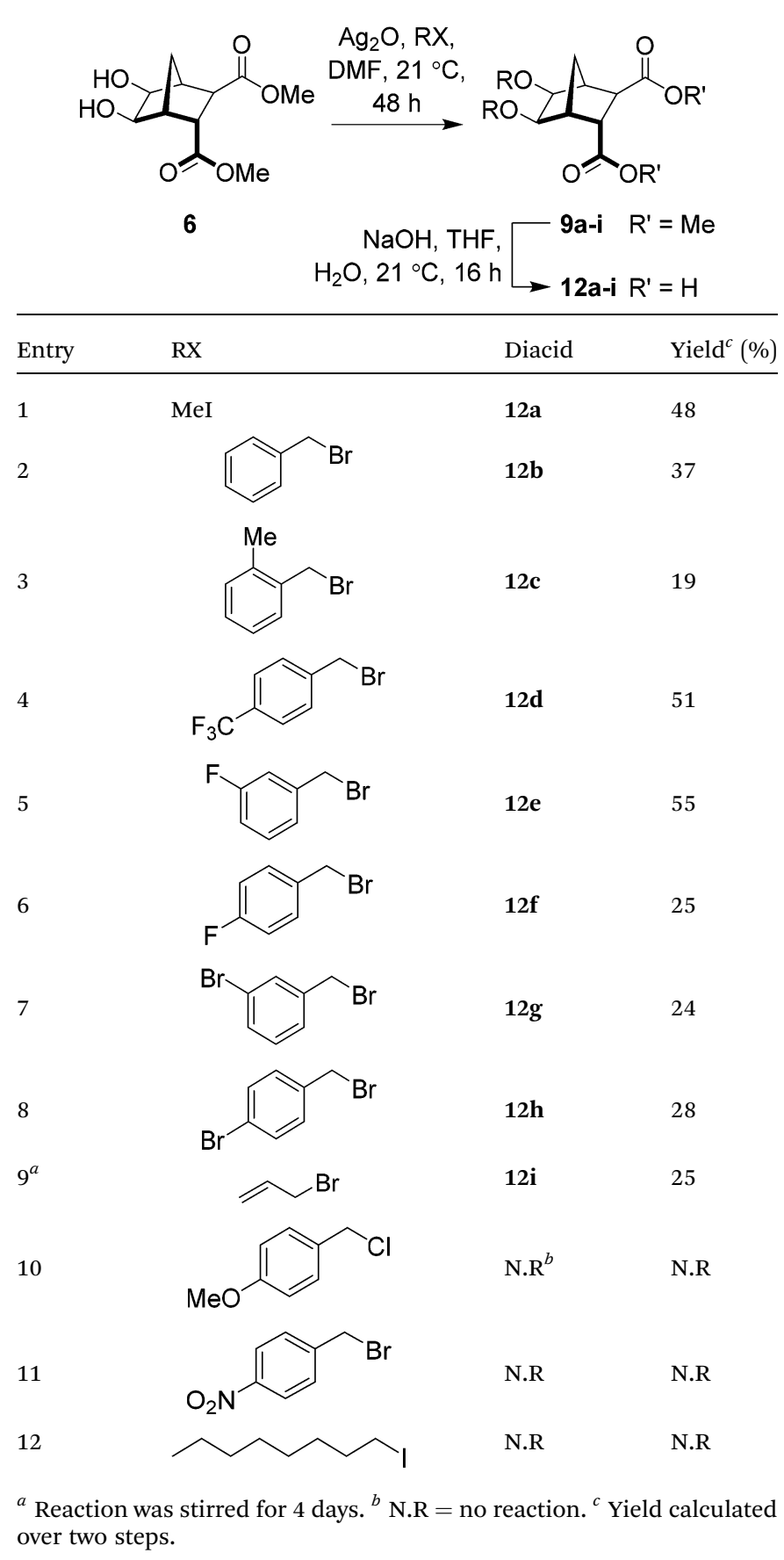

In six of the alkylation reactions $(\mathbf{1 2 b}, \mathbf{1 2 d}-\mathbf{h})$ transesterification occurred to a small extent $(6-12 \%$, as determined using ${ }^{1} \mathrm{H}$ NMR spectroscopy). This mixed-ester side-product (example 13 from synthesis of 9b, Fig. 3) was difficult to separate from the desired dimethyl ester product using column chromatography. The presumption that the more sterically accessible exo methyl ester was replaced is based on a previous report by Niwayama and co-workers that illustrated how the exo face is less hindered than the endo face of related norbornane diesters. ${ }^{40}$ Despite the presence of small amounts of mixed-ester 

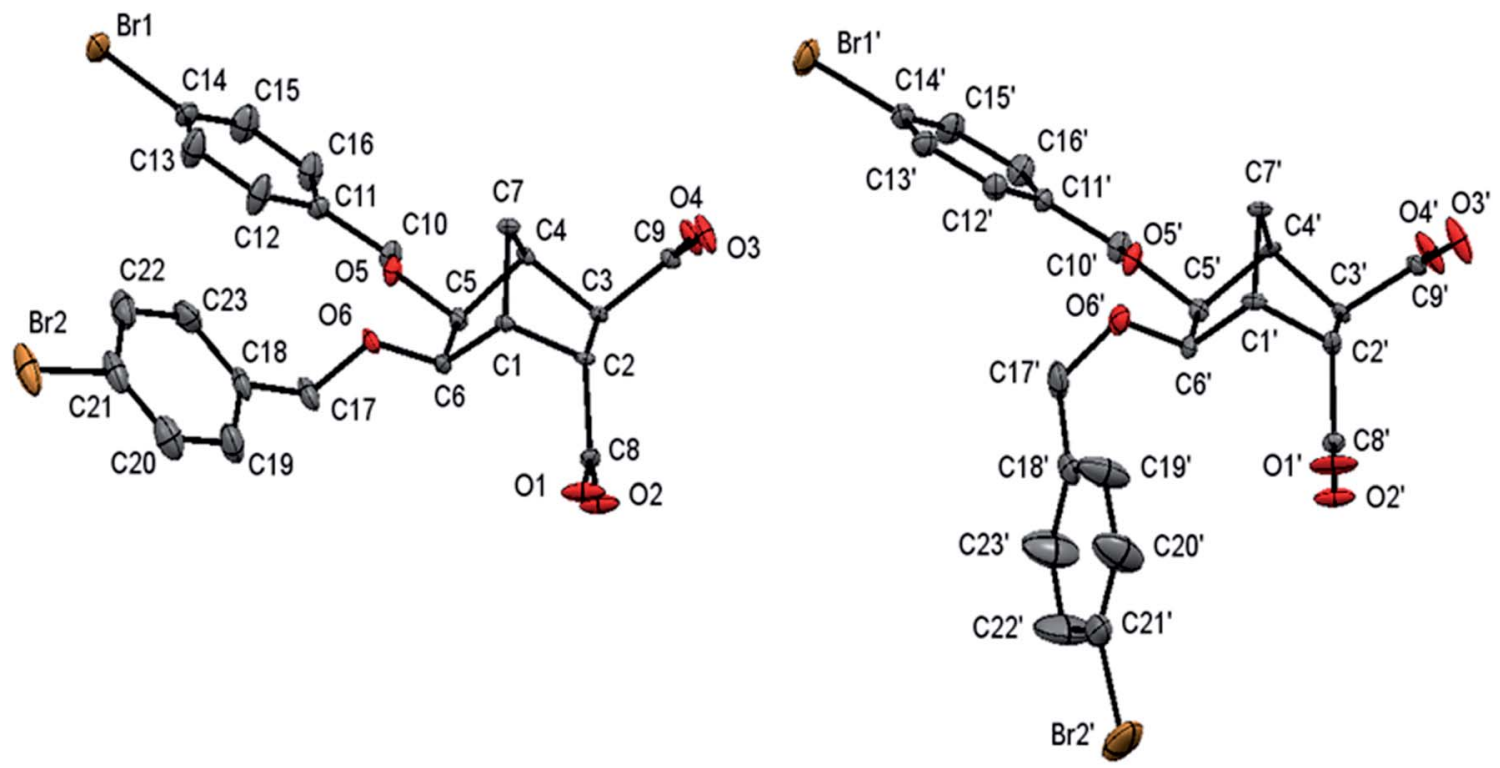

Fig. 2 Thermal ellipsoid plot of the two independent molecular confirmations (ellipsoids at 20\% probability level) of compound $12 \mathrm{~h}$.

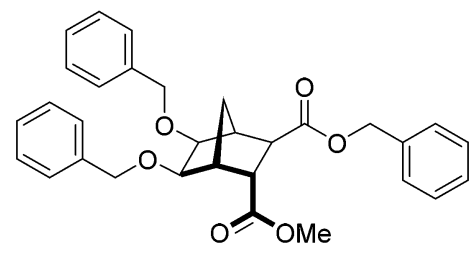

13

Fig. 3 Representative structure of proposed mixed-ester 13 formed during reaction with $\mathrm{BnBr}$.

by-products, in each case hydrolysis proceeded smoothly and pure diacids were isolated in every instance.

With bisethers diacids (12a-i) in hand, functionalization to the required amphiphiles was pursued. Attachment of 2-[2,3bis(tert-butoxycarbonyl)guanidino]ethylamine $(\mathbf{1 4})^{47,48}$ to the norbornane scaffold was carried out using EDCI and HOBt in either DMF or $\mathrm{CHCl}_{3}$ using microwave irradiation at $50^{\circ} \mathrm{C}$ for 30 minutes to give compounds 15a-i in moderate to good yields (26-72\%, Table 2). Subsequent deprotection was accomplished using $\mathrm{HCl}$ (generated in situ from $\mathrm{AcCl}$ in $\mathrm{MeOH}$ ) to give the desired guanidines as the guanidinium chloride salts $(\mathbf{1 6 a}-\mathbf{i}$, Table 2).

A balance of both hydrophobicity and hydrophilicity is essential for the antibacterial activity of structural amphiphiles. ${ }^{49}$ In light of this, the calculated $\log P(c \log P)$ values (the $\log$ of the octanol/water partition coefficient) were determined for bisether diguanidines (16a-i) using http://www. molinspiration.com software (Table 2) and these will be discussed in relation to activity in the following section.

\section{Biological evaluation}

The antibacterial activity of these compounds was evaluated against a range of Gram-negative and Gram-positive bacteria, including members of the ESKAPE pathogens; ${ }^{1}$ first using the disk diffusion assay to identify active compounds then microbroth dilution assays to determine minimum inhibitory concentrations (MICs).

Bis-methyl ether 16a and allyl ether 16i, did not show any inhibition in disk diffusion studies at $50 \mu \mathrm{g}$ per disk (Table 3). For the bis-benzyl ether $\mathbf{1 6 b}$, a noticeable zone of inhibition (ZOI) was observed $(11 \mathrm{~mm})$ against Pseudomonas aeruginosa. The inclusion of small substituents to the phenyl rings, such as 2-methyl (16c), 3-fluoro (16e) and 4-fluoro (16f), led to improved activity as shown by ZOI's of $14-16 \mathrm{~mm}$ against $P$. aeruginosa and Klebsiella pneumoniae (Table 3). Furthermore, appreciable ZOI's (11-15 mm) were also observed against Gram-positive methicillin-resistant Staphylococcus aureus (MRSA). When larger substituents occupied the 4-position of the phenyl ring, inhibition of vancomycin-resistant Enterococcus faecium (VRE) was also seen in addition to the aforementioned strains. The 4(trifluoromethyl)benzyl (16d) and 4-bromobenzyl (16h) analogs showed ZOI of 18 and $16 \mathrm{~mm}$ respectively for VRE (Table 3 ). The 3-bromobenzyl derivative (16g) was active against all pathogens assessed in this study, and was the sole compound to exhibit activity against Acinetobacter baumannii (ZOI $=15 \mathrm{~mm}$ ). Comparison of ZOI between $16 \mathrm{~g}$ and $16 \mathrm{~h}$ indicates that activity against $A$. baumannii, $K$. pneumoniae and $E$. faecium can be influenced by subtle changes to substituent locations and may have implications in the design of subsequent compounds.

Given the promising results in the disk diffusion screen the substituted benzyl ethers were subjected to a micro-broth dilution assay to quantify MICs (Table 4). When smaller substituents; 2-methyl (16c), 3-fluoro (16e) and 4-fluoro (16f) displaying no MIC $\leq 32 \mu \mathrm{g} \mathrm{mL} \mathrm{m}^{-1}$ against any bacterial strain tested (Table 4). When larger substituents were included on the benzyl rings such as 4-(trifluoromethyl)benzyl (16d) MIC values of $32 \mu \mathrm{g} \mathrm{mL} \mathrm{m}^{-1}$ against $A$. baumannii, and $8 \mu \mathrm{g} \mathrm{mL} \mathrm{m}^{-1}$ against each of $P$. aeruginosa, Escherichia coli and MRSA (Table 4) were 
Table 2 Formation of $\mathrm{HCl}$ salts $16 \mathrm{a}-\mathrm{i}$ and associated $c \log P$ values

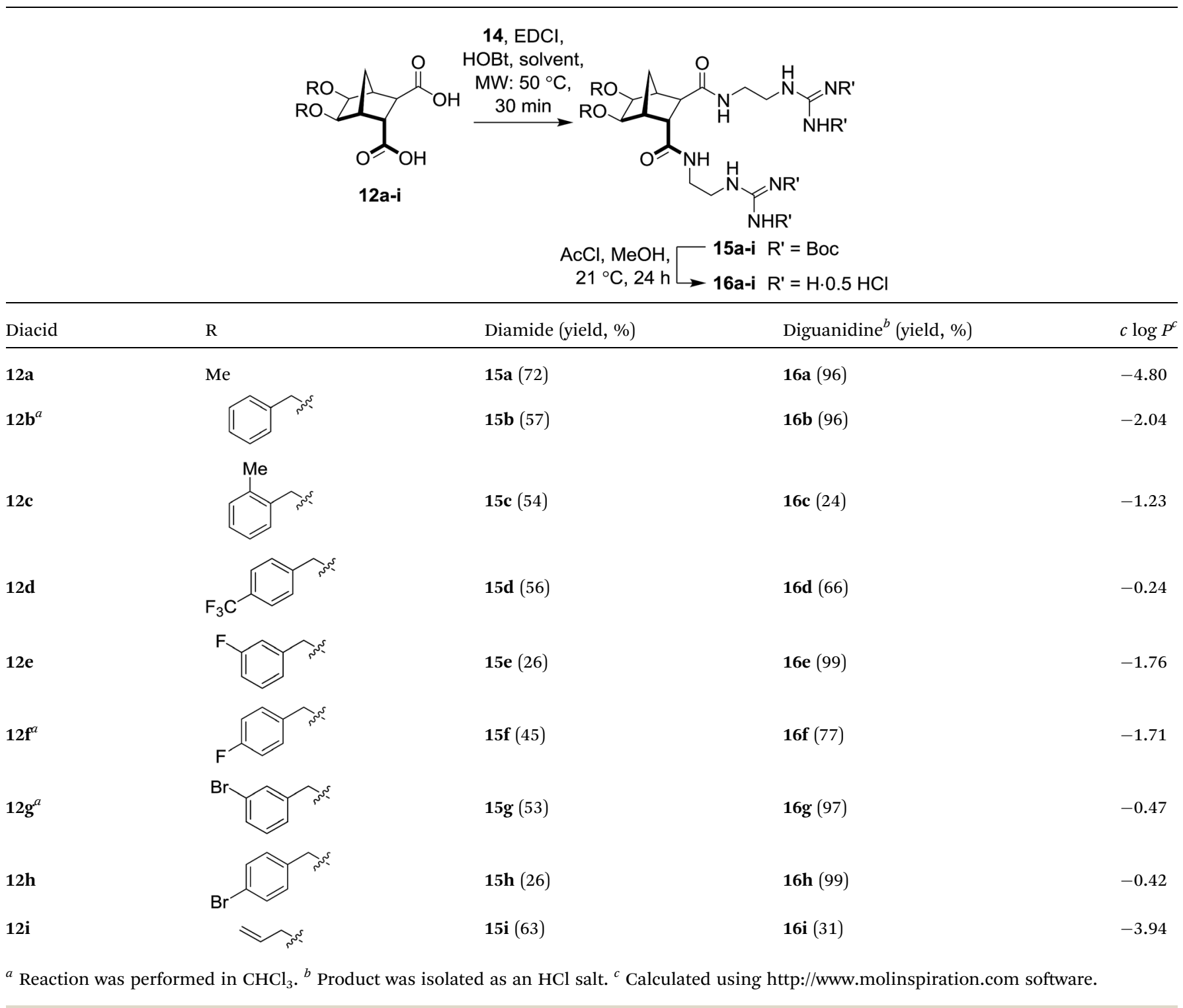

observed. The 3-bromo benzyl-substituted analog (16g) showed a reasonable MIC against both Gram-negative $P$. aeruginosa $(32$ $\left.\mu \mathrm{g} \mathrm{mL}^{-1}\right)$ and Gram-positive MRSA $\left(16 \mu \mathrm{g} \mathrm{mL}^{-1}\right)$ bacterial strains. Furthermore, an MIC of $32 \mu \mathrm{g} \mathrm{mL}{ }^{-1}$ was observed for the 4-bromo benzyl-substituted analog (16h) against MRSA
(Table 4). A correlation between antibacterial activity and $c \log P$ was apparent with compounds with higher $c \log P$ values (Table 2) showing stronger antibacterial activity.

Given the encouraging MIC values for compounds $\mathbf{1 6 d}$ and $16 \mathrm{~g}$ against MRSA (Table 4), both compounds were evaluated

Table 3 Zone of inhibition (ZOI) as measured (in $\mathrm{mm}$ ) using disk diffusion ${ }^{a}$

\begin{tabular}{|c|c|c|c|c|c|c|c|c|c|c|}
\hline & \multicolumn{10}{|c|}{ Compound } \\
\hline & $16 \mathbf{a}$ & $16 b$ & $16 \mathrm{c}$ & $16 d$ & $16 e$ & $16 f$ & $16 \mathrm{~g}$ & $16 \mathrm{~h}$ & $16 i$ & $\mathrm{COL}^{c}$ \\
\hline A. baumannii ATCC 19606 & $\mathrm{NT}^{b}$ & NT & - & - & - & - & 15 & - & - & \\
\hline P. aeruginosa ATCC 27853 & - & 11 & 16 & 15 & 16 & 15 & $16^{d}$ & 15 & - & 19 \\
\hline K. pneumoniae АТCC13883 & - & - & 14 & 16 & 14 & 14 & 15 & 8 & - & 20 \\
\hline S. aureus MRSA ATCC 43300 & - & - & 15 & 17 & 11 & 11 & $17^{d}$ & 18 & - & - \\
\hline E. faecium VRE ATCC 700221 & - & - & - & 18 & - & - & 7 & 16 & - & - \\
\hline
\end{tabular}

${ }^{a}$ Measured after incubation of disk $(6 \mathrm{~mm}$ diameter, $50 \mu$ g per disk $)$ at $37^{\circ} \mathrm{C}$ for 20 hours. ${ }^{b} \mathrm{NT}=$ not tested. ${ }^{c}$ Tested at $10 \mu \mathrm{g}$ per disk. ${ }^{d}$ As seen in Fig. 4. 


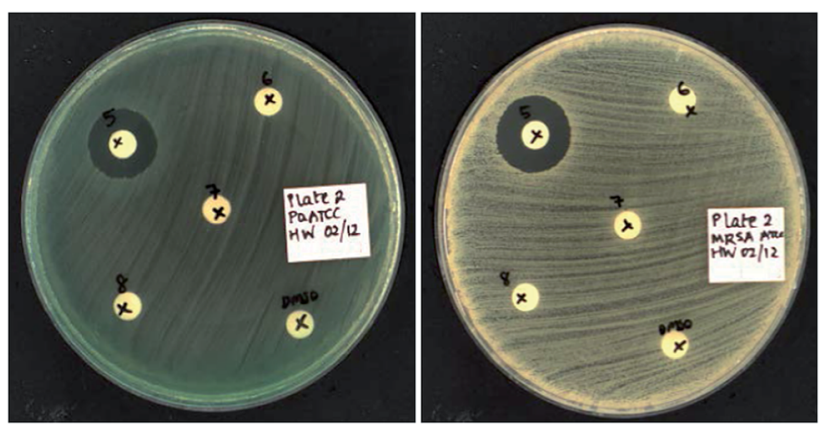

Fig. 4 Antibacterial activity of compound $16 \mathrm{~g}$ (50 $\mu \mathrm{g}$ per disk) against $P$. aeruginosa (LHS) and MRSA (RHS) using a disk diffusion assay.

against seven additional Gram-positive bacterial strains including such $S$. aureus bacterial isolates as multi-resistant methicillin resistant (mMRSA), glycopeptide-intermediate (GISA) and vancomycin-intermediate (VISA), as well as Streptococcus pneumoniae and E. faecalis (Table 5). The 4-(trifluoromethyl)benzyl bisether (16d) was again the most active compound; exhibiting antibacterial activity (MIC $=8-16 \mu \mathrm{g}$ $\mathrm{mL}^{-1}$ ) against all eight bacterial strains tested. Furthermore, activity was observed by 3-bromobenzyl bisether (16g) against all Gram-positive bacterial strains tested which was highlighted by an MIC of $8 \mu \mathrm{g} \mathrm{mL} \mathrm{m}^{-1}$ against $S$. pneumoniae (Table 4).

The cell viability (\% survival) against human embryonic kidney cells (HEK293) and hepatocellular carcinoma (HepG2) was determined after exposure to compounds $16 \mathrm{~d}$ or $16 \mathrm{~g}$ at 100 $\mu \mathrm{M}$ for 24 hours (Table 5). The 4-(trifluoromethyl)benzyl bisether (16d) exhibited moderate cytotoxicity with 43 and 56\% cell survival observed against HEK293 and HepG2 respectively (Table 5). In the case of bis-3-bromobenzyl ether $(\mathbf{1 6 g})$ the cell viability was determined to be $90 \%$ and 96\% against HEK293 and HepG2 respectively $\left(\mathrm{IC}_{50}<100 \mu \mathrm{M}\right)$. The cytotoxicity profile for these compounds is acceptable when compared to previously reported antibacterial agents. ${ }^{\mathbf{5 0}}$
Table 5 Cytotoxicity values (\% of cell survival at $24 \mathrm{~h}$ )

\begin{tabular}{lll}
\hline & \multicolumn{2}{l}{ Compound } \\
\cline { 2 - 3 } & $\mathbf{1 6 d}$ & $\mathbf{1 6 g}$ \\
\hline ATCC CRL-1573 HEK293 & 43 & 90 \\
ATCC HB-8065 HepG2 & 56 & 96
\end{tabular}

\section{Conclusions}

The previously inaccessible norbornane bisether diacids 12a-i, were successfully prepared using $\mathrm{Ag}_{2} \mathrm{O}$ and a suitable alkyl or benzyl halide as the key step. An X-ray crystal structure of bisether diacid $\mathbf{1 2 h}$ highlighted the sterically crowded environment of the ethers; which presumably hindered the second etherification step and resulted in lower yields. Nevertheless, the protocol presented here provides a viable alternative for the alkylation of congested syn-diols or base-sensitive alcohols where typical Williamson ether synthesis conditions fail. Further functionalization of bisether diacids (12a-i) gave a series of bisguanidines as hydrochloride salts (16a-i).

Several of the compounds (16d, 16g and 16h) displayed antibacterial activity, with MIC values as low as $8 \mu \mathrm{g} \mathrm{mL} \mathrm{mL}^{-1}$, against a range of problematic bacterial species including $P$. aeruginosa, E. coli, S. pneumonia, E. faecalis and several strains of $S$. aureus. The results presented here reinforce the notion that the activity of cationic antimicrobial peptides can be mimicked by relatively small, structurally rigid amphiphiles. Indeed, when compared to other synthetic scaffolds (such as calixarenes) which are used to generate antibacterial amphiphiles, ${ }^{9}$ the low molecular weight of these compounds and their reasonable antibacterial activity make them an attractive class of compounds worthy of further investigation.

\section{Experimental section}

The following compounds were prepared using literature methods and full reaction details can be found in the ESI; $\uparrow$ dimethyl bicyclo[2.2.1] hept-5-ene-3-endo-2-exo-dicarboxylate $(17),{ }^{39,51} 6^{16,41}$ and $14 .{ }^{47}$

Table 4 MIC values $\left(\mu \mathrm{g} \mathrm{mL}^{-1}\right)$

\begin{tabular}{|c|c|c|c|c|c|c|c|c|}
\hline & \multicolumn{8}{|c|}{ Compound } \\
\hline & $16 c$ & 16d & $16 e$ & $16 f$ & $16 \mathrm{~g}$ & $16 h$ & $\mathrm{COL}^{b}$ & $\operatorname{VAN}^{c}$ \\
\hline A. baumannii ATCC 19606 & $>32$ & 32 & $>32$ & $>32$ & $>32$ & $>32$ & 0.06 & NT \\
\hline P. aeruginosa ATCC 27853 & $>32$ & 8 & $>32$ & $>32$ & 32 & $>32$ & 0.25 & NT \\
\hline K. pneumoniae ATCC 700603 & $>32$ & $>32$ & $>32$ & $>32$ & $>32$ & $>32$ & 0.03 & NT \\
\hline E. coli ATCC 25922 & $>32$ & 8 & $>32$ & $>32$ & $>32$ & $>32$ & 0.06 & NT \\
\hline S. aureus MRSA ATCC 43300 & $>32$ & 8 & $>32$ & $>32$ & 16 & 32 & NT & 1 \\
\hline S. aureus mMRSA & $\mathrm{NT}^{a}$ & 16 & NT & NT & 32 & NT & NT & 1 \\
\hline S. aureus GISA, NRS 17 & NT & 8 & NT & NT & 16 & NT & NT & 4 \\
\hline S. aureus VISA, NRS 1 & NT & 16 & NT & NT & 32 & NT & NT & 8 \\
\hline S. aureus MRSA & NT & 16 & NT & NT & 32 & NT & NT & 2 \\
\hline S. aureus NARSA VRS 10 & NT & 8 & NT & NT & 16 & NT & NT & 2 \\
\hline S. pneumoniae MDR ATCC 700677 & NT & 8 & NT & NT & 8 & NT & NT & 2 \\
\hline VanA E. faecalis & NT & 8 & NT & NT & 32 & NT & NT & $>32$ \\
\hline
\end{tabular}




\section{General information}

All microwave reactions were conducted using a CEM Discover S-Class Explorer 48 Microwave Reactor, operating on a frequency of $50 / 60 \mathrm{~Hz}$ and continuous irradiation power from 0-300 W. All reactions were performed in sealed reaction vessels. All melting points are uncorrected. All ${ }^{1} \mathrm{H},{ }^{13} \mathrm{C}$ and ${ }^{19} \mathrm{~F}$ NMR spectra were collected on either a $270 \mathrm{MHz}$ FT-NMR spectrometer, a $400 \mathrm{MHz}$ FT-NMR spectrometer, or a $500 \mathrm{MHz}$ FT-NMR spectrometer where indicated. All 2D NMR experiments were performed on a $500 \mathrm{MHz}$ FT-NMR spectrometer. Variable temperature (VT) NMR experiments were performed on a $270 \mathrm{MHz}$ FT-NMR spectrometer. Samples were dissolved in $\mathrm{CDCl}_{3}$, DMSO- $d_{6}$ or $\mathrm{CD}_{3} \mathrm{OD}$ where specified with the residual solvent peak used as the internal reference $-\mathrm{CDCl}_{3} ; 7.26\left({ }^{1} \mathrm{H}\right)$ and $77.0\left({ }^{13} \mathrm{C}\right)$, DMSO- $d_{6} ; 2.50\left({ }^{1} \mathrm{H}\right)$ and $39.52\left({ }^{13} \mathrm{C}\right), \mathrm{CD}_{3} \mathrm{OD} ; 3.31$ $\left({ }^{1} \mathrm{H}\right)$ and $49.0\left({ }^{13} \mathrm{C}\right) .{ }^{52}$ Proton spectra are reported as chemical shift $\delta$ (ppm) (integral, multiplicity ( $\mathrm{s}=$ singlet, br $\mathrm{s}=$ broad singlet, $\mathrm{d}=$ doublet, $\mathrm{t}=$ triplet, $\mathrm{q}=$ quartet, quin = quintet and $\mathrm{m}=$ multiplet), coupling constant ( $\mathrm{Hz})$, assignment). Carbon spectra are reported as chemical shift $\delta$ (ppm) (integral, multiplicity ( $\mathrm{d}=$ doublet and $\mathrm{q}=$ quartet), coupling constant $(\mathrm{Hz})$ ) were appropriate. Fluorine spectra are reported as chemical shift $\delta$ (ppm) and were externally referenced using $0.05 \% \alpha, \alpha, \alpha-$ trifluorotoluene in $\mathrm{CDCl}_{3} ;-63.72\left({ }^{19} \mathrm{~F}\right)$.

High resolution mass spectral data was collected on using a QTOF mass spectrometer (LC-1200 series) under the following conditions: gas temperature $\left(300{ }^{\circ} \mathrm{C}\right)$, nitrogen drying gas $\left(10.0 \mathrm{~L} \mathrm{~min}^{-1}\right)$, capillary voltage $(3500 \mathrm{~V})$, fragmentor $(140 \mathrm{~V})$, and nebuliser (45 psi) in a $80 \% \mathrm{MeCN}$ in $\mathrm{H}_{2} \mathrm{O}$ solvent system. Analyte solutions were prepared in HPLC grade methanol (conc. $\sim 1 \mathrm{mg} \mathrm{mL}^{-1}$ ).

All chemicals and solvents were used as received without further purification unless otherwise stated. Column chromatography was performed on silica gel (230-400 mesh).

Dimethyl 5,6-diacetate bicyclo[2.2.1] heptane-3-endo-2-exodicarboxylate (20). The stirring solution of diol 6 (130 mg, 0.532 mmol), DMAP (13 mg, $0.11 \mathrm{mmol})$, pyridine (171 $\mu \mathrm{L}, 2.13 \mathrm{mmol})$ and $\mathrm{CH}_{2} \mathrm{Cl}_{2}(1.1 \mathrm{~mL})$ was treated with $\mathrm{AcCl}(130 \mu \mathrm{L}, 1.81 \mathrm{mmol})$ slowly and the reaction was stirred at ambient temperature for $16 \mathrm{~h}$. The resulting bright orange solution was quenched with sat. $\mathrm{NaHCO}_{3}(6 \mathrm{~mL})$ and extracted with $\mathrm{CH}_{2} \mathrm{Cl}_{2}(3 \times 10 \mathrm{~mL})$. The combined organic phase was washed with $1 \mathrm{M} \mathrm{HCl}(10 \mathrm{~mL})$, dried $\left(\mathrm{MgSO}_{4}\right)$, filtered and concentrated in vacuo to give a clear oil that was purified by column chromatography (35-50\% EtOAc in pet. spirits). The title compound (110 mg, 63\%) was isolated as a clear oil; $R_{\mathrm{f}}=0.68$ (50\% EtOAc in pet. spirits). ${ }^{1} \mathrm{H}$ NMR $(270$ $\left.\mathrm{MHz}, \mathrm{CDCl}_{3}\right) \delta 1.53(1 \mathrm{H}, \mathrm{dt}, J=11.0,1.4 \mathrm{~Hz}, \mathrm{H} 7 \mathrm{~s}), 1.94(1 \mathrm{H}, \mathrm{dd}$, $J=11.0,1.6 \mathrm{~Hz}, \mathrm{H} 7 \mathrm{a}), 2.01$ (6H, s, $2 \times \mathrm{Me}), 2.61$ (1H, br s, H1), 2.64-2.66 (1H, m, H4), 2.87 (1H, dd, $J=5.6,1.2 \mathrm{~Hz}, \mathrm{H} 2), 3.23$ (1H, app. t, $J=5.6 \mathrm{~Hz}, \mathrm{H} 3), 3.69$ ( $3 \mathrm{H}, \mathrm{s}, \mathrm{Me}), 3.73(3 \mathrm{H}, \mathrm{s}, \mathrm{Me})$, $4.75(1 \mathrm{H}, \mathrm{dd}, J=6.0,1.6 \mathrm{~Hz}, \mathrm{H} 6), 4.87(1 \mathrm{H}, \mathrm{dd}, J=6.0,1.4 \mathrm{~Hz}$, H5). ${ }^{13} \mathrm{C}$ NMR $\left(67.5 \mathrm{MHz}, \mathrm{CDCl}_{3}\right) \delta 20.6,20.7,33.7,44.6,44.7$, 46.1, 46.2, 52.4, 52.5, 72.4, 74.8, 169.7, 169.9, 172.2, 173.7. HRMS (ESI, $m / z$ ) for $\mathrm{C}_{15} \mathrm{H}_{20} \mathrm{O}_{8}[\mathrm{M}+\mathrm{H}]^{+}$calc. 329.1231 found 329.1233 .

\section{General procedure A for the bis-alkylation of diol 6}

Anhydrous DMF $(2.4 \mathrm{~mL})$ was added to a pre-dried roundbottom flask protected from light, containing diol 6 (3.7 mmol) and $\mathrm{Ag}_{2} \mathrm{O}$ (1.6 equiv.) at ambient temperature. To the stirring solution was added the appropriate alkylating agent (4.6 equiv.) and the reaction was stirred for $48 \mathrm{~h}$ before the reaction vessel was cooled to $4{ }^{\circ} \mathrm{C}$ (refrigerator) for a further $16 \mathrm{~h}$ without agitation. The resulting precipitate was removed by vacuum filtration and washed with EtOAc $(15 \mathrm{~mL})$. The filtrate was washed with $\mathrm{H}_{2} \mathrm{O}(3 \times 10 \mathrm{~mL})$, dried $\left(\mathrm{MgSO}_{4}\right)$, filtered and concentrated in vacuo to afford the crude product which was purified by column chromatography to give the desired bisether.

Dimethyl 5,6-bis(methoxy) bicyclo[2.2.1]heptane-3-endo-2exo-dicarboxylate (9a). Compound 9a was prepared from diol 6 (915 $\mathrm{mg}, 3.74 \mathrm{mmol}$ ) and iodomethane $(1.1 \mathrm{~mL}, 17.7 \mathrm{mmol})$ according to general procedure A and was purified by column chromatography (20\% EtOAc in pet. spirits) to give the title compound (682 mg, 67\%) as a clear viscous oil; $R_{\mathrm{f}}=0.17(20 \%$ EtOAc in pet. spirits). ${ }^{1} \mathrm{H}$ NMR $\left(270 \mathrm{MHz}, \mathrm{CDCl}_{3}\right) \delta 1.39(1 \mathrm{H}$, dquin, $J=10.7,1.6 \mathrm{~Hz}, \mathrm{H} 7 \mathrm{~s}), 1.89(1 \mathrm{H}$, ddd, $J=10.7,1.6,1.5 \mathrm{~Hz}$, H7a), 2.64-2.69 (3H, m, H1, H2, H4), 3.20 (1H, dd, $J=5.5,0.8$ Hz, H3), 3.29 (1H, dd, J=6.0, $1.7 \mathrm{~Hz}, \mathrm{H} 5$ ), 3.37 (3H, s, Me), 3.42 (3H, s, Me), 3.46 (1H, dd, $J=6.1,1.8 \mathrm{~Hz}, \mathrm{H} 6), 3.70$ ( $3 \mathrm{H}, \mathrm{s}, \mathrm{Me})$, $3.72(3 \mathrm{H}, \mathrm{s}, \mathrm{Me}) .{ }^{13} \mathrm{C} \mathrm{NMR}\left(67.5 \mathrm{MHz}, \mathrm{CDCl}_{3}\right) \delta 32.9,43.3,44.8$, 45.0, 46.4, 52.2, 52.4, 58.7, 58.8, 81.0, 84.1, 173.2, 174.2. HRMS (ESI, $m / z$ ) for $\mathrm{C}_{13} \mathrm{H}_{20} \mathrm{O}_{6}[\mathrm{M}+\mathrm{H}]^{+}$calc. 273.1333; found 273.1328.

Dimethyl 5,6-bis(benzyloxy) bicyclo[2.2.1]heptane-3-endo-2exo-dicarboxylate (9b). Compound $9 b$ was prepared from diol 6 (917 $\mathrm{mg}, 3.75 \mathrm{mmol}$ ) and benzyl bromide $(2.1 \mathrm{~mL}, 17.3 \mathrm{mmol}$ ) according to general procedure A and was purified by column chromatography $(10 \%$ EtOAc in pet. spirits) to give the title compound (743 mg, 47\%) as a clear oil; $R_{\mathrm{f}}=0.43(20 \%$ EtOAc in pet. spirits). ${ }^{1} \mathrm{H}$ NMR (500 MHz, $\left.\mathrm{CDCl}_{3}\right) \delta 1.45(1 \mathrm{H}, \mathrm{dt}, J=10.7$, $1.5 \mathrm{~Hz}, \mathrm{H} 7 \mathrm{~s}), 2.10(1 \mathrm{H}, \mathrm{dd}, J=10.7,1.6 \mathrm{~Hz}, \mathrm{H} 7 \mathrm{a}), 2.64-2.65(2 \mathrm{H}$, m, H1, H2), 2.70-2.71 (1H, m, H4), 3.19 (1H, app. t, $J=5.3 \mathrm{~Hz}$, H3), 3.46 (1H, dd, $J=5.8,1.6 \mathrm{~Hz}, \mathrm{H} 5), 3.60$ (3H, s, Me), $3.62(1 \mathrm{H}$, $\mathrm{dd}, J=5.9,1.4 \mathrm{~Hz}, \mathrm{H} 6), 3.69$ (3H, s, Me), 4.53-4.62 (4H, m, $2 \times$ $\mathrm{ArCH}_{2}$ ), 7.25-7.38 (10H, m, ArH). ${ }^{13} \mathrm{C}$ NMR (125 MHz, $\left.\mathrm{CDCl}_{3}\right) \delta$ 33.4, 44.2, 45.1, 45.9, 46.4, 52.2, 52.4, 72.5, 72.7, 77.9, 81.7, 127.7 $(2 \times \mathrm{C}), 127.9(2 \times \mathrm{C}), 128.0(2 \times \mathrm{C}), 128.4(2 \times \mathrm{C}), 128.5(2 \times \mathrm{C})$, 138.4, 138.5, 173.1, 174.3. HRMS (ESI, $m / z$ ) for $\mathrm{C}_{25} \mathrm{H}_{28} \mathrm{O}_{6}[\mathrm{M}+$ $\mathrm{Na}]^{+}$calc. 447.1778; found 447.1754.

Dimethyl 5,6-bis[(2-methylbenzyl)oxy] bicyclo[2.2.1]heptane3-endo-2-exo-dicarboxylate (9c). Compound 9c was prepared from diol 6 (321 mg, $1.31 \mathrm{mmol}$ ) and 2-methylbenzyl bromide $(810 \mu \mathrm{L}, 6.03 \mathrm{mmol})$ according to general procedure A and was purified by column chromatography (10-20\% EtOAc in pet. spirits) to give the title compound (115 mg, 19\%) as a clear oil; $R_{\mathrm{f}}=0.50$ (20\% EtOAc in pet. spirits). ${ }^{1} \mathrm{H} \mathrm{NMR}\left(500 \mathrm{MHz}, \mathrm{CDCl}_{3}\right)$ $\delta 1.45(1 \mathrm{H}, \mathrm{d}, J=10.6 \mathrm{~Hz}, \mathrm{H} 7 \mathrm{~s}), 2.10(1 \mathrm{H}, \mathrm{dd}, J=10.6,1.4 \mathrm{~Hz}$, H7a), 2.27 (3H, s, ArMe), 2.30 (3H, s, ArMe), 2.67-2.68 (2H, m, H1, H2), 2.70-2.71 (1H, m, H4), 3.19 (1H, app. t, $J=5.3 \mathrm{~Hz}, \mathrm{H} 3$ ), $3.49(1 \mathrm{H}, \mathrm{dd}, J=5.8,1.4 \mathrm{~Hz}, \mathrm{H} 5), 3.62$ (3H, s, Me), 3.64 (1H, dd, $J=5.7,1.2 \mathrm{~Hz}, \mathrm{H} 6), 3.70(3 \mathrm{H}, \mathrm{s}, \mathrm{Me}), 4.49-4.61(4 \mathrm{H}, \mathrm{m}, 2 \times$ $\mathrm{ArCH}_{2}$ ), 7.10-7.20 (6H, m, ArH), 7.24-7.25 (1H, m, ArH), 7.31- 
$7.33(1 \mathrm{H}, \mathrm{m}, \mathrm{ArH}) .{ }^{13} \mathrm{C} \mathrm{NMR}\left(125 \mathrm{MHz}, \mathrm{CDCl}_{3}\right) \delta$ 18.9, 19.0, 33.4, $44.4,45.1,45.7,46.5,52.2$, 52.4, 70.9, 71.0, 78.3, 82.0, 125.8, 125.9, $127.8(2 \times \mathrm{C}), 128.8,128.9,130.2,130.3,136.3,136.4$, 136.7, 136.9, 173.2, 174.3. HRMS (ESI, $m / z$ ) for $\mathrm{C}_{27} \mathrm{H}_{32} \mathrm{O}_{6}[\mathrm{M}+$ $\mathrm{Na}]^{+}$calc. 475.2091; found 475.2073.

Dimethyl 5,6-bis[(4-trifluoromethyl)benzyloxy] bicyclo[2.2.1]heptane-3-endo-2-exo-dicarboxylate (9d). Compound 9d was prepared from diol $6(315 \mathrm{mg}, 1.29 \mathrm{mmol})$ and 4-(trifluoromethyl)benzyl bromide ( $910 \mu \mathrm{L}, 5.93 \mathrm{mmol})$ according to general A procedure and was purified by column chromatography $(10-20 \%$ EtOAc in pet. spirits) to give the title compound (461 mg, 64\%) as a clear oil; $R_{\mathrm{f}}=0.26(20 \%$ EtOAc in pet. spirits). ${ }^{1} \mathrm{H}$ NMR (500 MHz, $\left.\mathrm{CDCl}_{3}\right) \delta 1.49(1 \mathrm{H}, \mathrm{dt}, J=10.7$, $1.4 \mathrm{~Hz}, \mathrm{H} 7 \mathrm{~s}), 2.10(1 \mathrm{H}, \mathrm{dd}, J=10.7,1.6 \mathrm{~Hz}, \mathrm{H} 7 \mathrm{a}), 2.66-2.68(2 \mathrm{H}$, m, H1, H2), 2.72-2.75 (1H, m, H4), $3.22(1 \mathrm{H}$, app. t, $J=5.2 \mathrm{~Hz}$, H3), 3.52 (1H, dd, $J=5.8,1.6 \mathrm{~Hz}, \mathrm{H} 5), 3.63(3 \mathrm{H}, \mathrm{s}, \mathrm{Me}), 3.67(1 \mathrm{H}$, $\mathrm{dd}, J=5.8,1.4 \mathrm{~Hz}, \mathrm{H} 6), 3.71$ (3H, s, Me), 4.57-4.68 (4H, m, $2 \times$ $\mathrm{ArCH}_{2}$ ), 7.38-7.42 (4H, m, ArH), 7.54-7.57 (4H, m, ArH). ${ }^{13} \mathrm{C}$ NMR $\left(125 \mathrm{MHz}, \mathrm{CDCl}_{3}\right) \delta 33.3,44.2,45.0,45.8,46.3,52.3,52.5,71.8$, $71.9,78.6,82.2,124.2\left(\mathrm{q}, J_{\mathrm{CF}}=270.6 \mathrm{~Hz}, 2 \times \mathrm{CF}_{3}\right), 125.3\left(\mathrm{q},{ }^{3} J_{\mathrm{CF}}=\right.$ $3.6 \mathrm{~Hz}, 2 \times \mathrm{CH}), 125.4\left(\mathrm{q},{ }^{3} J_{\mathrm{CF}}=3.6 \mathrm{~Hz}, 2 \times \mathrm{CH}\right), 127.7(2 \times \mathrm{C})$, $127.8(2 \times \mathrm{C}), 129.9\left(\mathrm{q},{ }^{2} J_{\mathrm{CF}}=32.3 \mathrm{~Hz}\right), 130.0\left(\mathrm{q},{ }^{2} J_{\mathrm{CF}}=32.3 \mathrm{~Hz}\right)$, 142.4 $(2 \times \mathrm{C}), 173.1,174.0 .{ }^{19} \mathrm{~F}$ NMR $\left(470 \mathrm{MHz}, \mathrm{CDCl}_{3}\right) \delta-63.02$, -63.00. HRMS (ESI, $m / z$ ) for $\mathrm{C}_{27} \mathrm{H}_{26} \mathrm{~F}_{6} \mathrm{O}_{6}[\mathrm{M}+\mathrm{H}]^{+}$calc. 561.1706; found 561.1718 .

Dimethyl 5,6-bis[(3-fluorobenzyl)oxy] bicyclo[2.2.1]heptane3-endo-2-exo-dicarboxylate (9e). Compound 9e was prepared from diol 6 (333 mg, $1.36 \mathrm{mmol}$ ) and 3-fluorobenzyl bromide $(770 \mu \mathrm{L}, 6.26 \mathrm{mmol})$ according to general procedure A and was purified by column chromatography (10-20\% EtOAc in pet. spirits) to give the title compound (326 mg, 52\%) as a clear oil; $R_{\mathrm{f}}=0.31$ (20\% EtOAc in pet. spirits). ${ }^{1} \mathrm{H}$ NMR (500 MHz, $\mathrm{CDCl}_{3}$ ) $\delta 1.47(1 \mathrm{H}, \mathrm{dt}, J=10.7,1.5 \mathrm{~Hz}, \mathrm{H} 7 \mathrm{~s}), 2.09$ (1H, dd, $J=10.7,1.6$ Hz, H7a), 2.65-2.67 (2H, m, H1, H2), 2.73 (1H, m, H4), 3.21 (1H, app. t, $J=5.3 \mathrm{~Hz}, \mathrm{H} 3), 3.47(1 \mathrm{H}, \mathrm{dd}, J=5.9,1.6 \mathrm{~Hz}, \mathrm{H} 5), 3.62-$ 3.64 (4H, m, Me, H6), 3.70 (3H, s, Me), 4.52-4.62 (4H, m, $2 \times$ $\mathrm{ArCH}_{2}$ ), 6.94-7.13 (6H, m, ArH), 7.25-7.30 (2H, m, ArH). ${ }^{13} \mathrm{C}$ NMR (125 MHz, $\left.\mathrm{CDCl}_{3}\right) \delta 33.3,44.1,45.0,45.8,46.3,52.2,52.5$, 71.7, 71.9, 78.2, 81.9, $114.52\left(\mathrm{~d},{ }^{2} J_{\mathrm{CF}}=21.6 \mathrm{~Hz}, 2 \times \mathrm{CH}\right), 114.59$ $\left(\mathrm{d},{ }^{2} J_{\mathrm{CF}}=21.1 \mathrm{~Hz}\right), 114.62\left(\mathrm{~d},{ }^{2} J_{\mathrm{CF}}=21.6 \mathrm{~Hz}\right), 123.07\left(\mathrm{~d},{ }^{3} J_{\mathrm{CF}}=\right.$ $2.8 \mathrm{~Hz}), 123.23\left(\mathrm{~d},{ }^{3} J_{\mathrm{CF}}=2.8 \mathrm{~Hz}\right), 129.94\left(\mathrm{~d},{ }^{4} J_{\mathrm{CF}}=1.6 \mathrm{~Hz}\right)$, $130.00\left(\mathrm{~d},{ }^{4} J_{\mathrm{CF}}=1.7 \mathrm{~Hz}\right), 140.98\left(\mathrm{~d},{ }^{3} J_{\mathrm{CF}}=2.4 \mathrm{~Hz}\right), 141.04\left(\mathrm{~d},{ }^{3} J_{\mathrm{CF}}\right.$ $=2.3 \mathrm{~Hz}), 163.00\left(\mathrm{~d},{ }^{1} J_{\mathrm{CF}}=244.6 \mathrm{~Hz}\right), 163.05\left(\mathrm{~d}, J_{\mathrm{CF}}=244.4 \mathrm{~Hz}\right)$, 173.1, 174.1. ${ }^{19} \mathrm{~F}$ NMR $\left(470 \mathrm{MHz}, \mathrm{CDCl}_{3}\right) \delta-113.77$. HRMS (ESI, $m / z)$ for $\mathrm{C}_{25} \mathrm{H}_{26} \mathrm{~F}_{2} \mathrm{O}_{6}[\mathrm{M}+\mathrm{H}]^{+}$calc. 461.1770; found 461.1784.

Dimethyl 5,6-bis[(4-fluorobenzyl)oxy] bicyclo[2.2.1]heptane3-endo-2-exo-dicarboxylate (9f). Compound 9 f was prepared from diol 6 (308 mg, $1.26 \mathrm{mmol}$ ) and 4-fluorobenzyl bromide $(720 \mu \mathrm{L}, 5.80 \mathrm{mmol}$ ) according to general procedure A and was purified by column chromatography (10-20\% EtOAc in pet. spirits) to give the title compound (157 mg, 27\%) as a clear oil; $R_{\mathrm{f}}=0.30$ (20\% EtOAc in pet. spirits). ${ }^{1} \mathrm{H} \mathrm{NMR}\left(500 \mathrm{MHz}, \mathrm{CDCl}_{3}\right)$ $\delta 1.45(1 \mathrm{H}, \mathrm{dt}, J=10.7,1.5 \mathrm{~Hz}, \mathrm{H} 7 \mathrm{~s}), 2.07$ (1H, dd, $J=10.7,1.6$ Hz, H7a), 2.64-2.65 (1H, m, H2), 2.66 (1H, m, H1), 2.69 (1H, dd, $=4.6,1.4 \mathrm{~Hz}, \mathrm{H} 4), 3.20(1 \mathrm{H}$, app. $\mathrm{t}, J=5.1 \mathrm{~Hz}, \mathrm{H} 3), 3.47(1 \mathrm{H}, \mathrm{dd}$, $J=5.8,1.6 \mathrm{~Hz}, \mathrm{H} 5), 3.62(1 \mathrm{H}, \mathrm{dd}, J=5.8,1.5 \mathrm{~Hz}, \mathrm{H} 6), 3.64(3 \mathrm{H}, \mathrm{s}$, $\mathrm{Me}), 3.70(3 \mathrm{H}, \mathrm{s}, \mathrm{Me}), 4.47-4.53\left(2 \mathrm{H}, \mathrm{m}, \mathrm{ArCH}_{2}\right), 4.54(2 \mathrm{H}, \mathrm{m}$,
$\mathrm{ArCH}_{2}$ ), 6.96-7.01 (4H, m, ArH), 7.23-7.30 (4H, m, ArH). ${ }^{13} \mathrm{C}$ NMR (125 MHz, $\mathrm{CDCl}_{3}$ ) $\delta 33.3,44.2,45.1,45.9,46.3,52.2,52.4$, 71.8, 72.0, 78.1, 81.8, $115.2\left(\mathrm{~d},{ }^{2} J_{\mathrm{CF}}=21.2 \mathrm{~Hz}, 2 \times \mathrm{CH}\right), 115.3(\mathrm{~d}$, $\left.{ }^{2} J_{\mathrm{CF}}=21.1 \mathrm{~Hz}, 2 \times \mathrm{CH}\right), 129.6\left(\mathrm{~d},{ }^{3} J_{\mathrm{CF}}=9.2 \mathrm{~Hz}, 2 \times \mathrm{CH}\right), 129.7$ $\left(\mathrm{d},{ }^{3} J_{\mathrm{CF}}=8.4 \mathrm{~Hz}, 2 \times \mathrm{CH}\right), 134.1\left(\mathrm{~d},{ }^{4} J_{\mathrm{CF}}=3.4 \mathrm{~Hz}\right), 134.2\left(\mathrm{~d},{ }^{4} J_{\mathrm{CF}}\right.$ $=2.9 \mathrm{~Hz}), 162.4\left(\mathrm{~d},{ }^{1} J_{\mathrm{CF}}=244.0 \mathrm{~Hz}\right), 162.5\left(\mathrm{~d},{ }^{1} J_{\mathrm{CF}}=244.3 \mathrm{~Hz}\right)$, 173.1, 174.1. ${ }^{19} \mathrm{~F}$ NMR (470 $\left.\mathrm{MHz}, \mathrm{CDCl}_{3}\right) \delta-115.36,-115.30$. HRMS (ESI, $m / z$ ) for $\mathrm{C}_{25} \mathrm{H}_{26} \mathrm{~F}_{2} \mathrm{O}_{6}[\mathrm{M}+\mathrm{Na}]^{+}$calc. 483.1590; found 483.1594.

Dimethyl 5,6-bis[(3-bromobenzyl)oxy] bicyclo[2.2.1]heptane3-endo-2-exo-dicarboxylate (9g). Compound $\mathbf{9 g}$ was prepared from diol 6 (315 mg, $1.29 \mathrm{mmol}$ ) and 3-bromobenzyl bromide (1.48 g, $5.93 \mathrm{mmol}$ ) according to general procedure A and was purified by column chromatography (10-20\% EtOAc in pet. spirits) to give the title compound (266 mg, 35\%) as a clear oil; $R_{\mathrm{f}}=0.27$ (20\% EtOAc in pet. spirits). ${ }^{1} \mathrm{H}$ NMR $\left(500 \mathrm{MHz}, \mathrm{CDCl}_{3}\right)$ $\delta 1.47(1 \mathrm{H}, \mathrm{dt}, J=10.7,1.4 \mathrm{~Hz}, \mathrm{H} 7 \mathrm{~s}), 2.09(1 \mathrm{H}, \mathrm{dd}, J=10.7,1.5$ $\mathrm{Hz}, \mathrm{H} 7 \mathrm{a}), 2.66-2.67$ (2H, m, H1, H2), 2.72 (1H, dd, $J=4.6,1.3$ $\mathrm{Hz}, \mathrm{H} 4), 3.21$ (1H, app. t, $J=4.9 \mathrm{~Hz}, \mathrm{H} 3), 3.48(1 \mathrm{H}, \mathrm{dd}, J=6.0$, $1.7 \mathrm{~Hz}, \mathrm{H} 5), 3.63$ (1H, dd, $J=5.7,1.4 \mathrm{~Hz}, \mathrm{H} 6), 3.66$ (3H, s, Me), $3.71(3 \mathrm{H}, \mathrm{s}, \mathrm{Me}), 4.49-4.59\left(4 \mathrm{H}, \mathrm{m}, 2 \times \mathrm{ArCH}_{2}\right), 7.15-7.29(4 \mathrm{H}$, $\mathrm{m}, \mathrm{ArH}), 7.39-7.53$ (4H, m, ArH). $\left.{ }^{13} \mathrm{C} \mathrm{NMR} \mathrm{(125} \mathrm{MHz}, \mathrm{CDCl}_{3}\right) \delta$ 33.3, 44.2, 45.1, 45.9, 46.3, 52.3, 52.5, 71.7, 71.9, 78.3, 82.0, 122.6, 122.7, 126.2, 126.3, $130.1(2 \times \mathrm{C}), 130.7,130.8(3 \times \mathrm{C})$, 140.7, 140.8, 173.1, 174.1. HRMS (ESI, $m / z$ ) for $\mathrm{C}_{25} \mathrm{H}_{26} \mathrm{Br}_{2} \mathrm{O}_{6}[\mathrm{M}+$ $\mathrm{H}]^{+}$calc. 581.0169; found 581.0181.

Dimethyl 5,6-bis[(4-bromobenzyl)oxy] bicyclo[2.2.1]heptane3-endo-2-exo-dicarboxylate (9h). Compound $9 \mathrm{~h}$ was prepared from diol 6 (333 mg, $1.36 \mathrm{mmol}$ ) and 4-bromobenzyl bromide (1.57 g, $6.26 \mathrm{mmol}$ ) according to general procedure A and was purified by column chromatography (10-20\% EtOAc in pet. spirits) to give the title compound (279 $\mathrm{mg}, 35 \%$ ) as a clear oil. $R_{\mathrm{f}}=0.36$ (20\% EtOAc in pet. spirits). $\left.{ }^{1} \mathrm{H} \mathrm{NMR} \mathrm{(500} \mathrm{MHz,} \mathrm{CDCl}_{3}\right)$ $\delta 1.45(1 \mathrm{H}, \mathrm{d}, J=10.7 \mathrm{~Hz}, \mathrm{H} 7 \mathrm{~s}), 2.06(1 \mathrm{H}, \mathrm{d}, J=10.6 \mathrm{~Hz}, \mathrm{H} 7 \mathrm{a})$, 2.64-2.65 (2H, m, H1, H2), 2.68-2.69 (1H, m, H4), 3.20 (1H, app. $\mathrm{t}, J=5.0 \mathrm{~Hz}, \mathrm{H} 3), 3.46(1 \mathrm{H}, \mathrm{dd}, J=5.8,1.6 \mathrm{~Hz}, \mathrm{H} 5), 3.61(1 \mathrm{H}, \mathrm{dd}$, $J=5.8,1.3 \mathrm{~Hz}, \mathrm{H} 6), 3.64$ (3H, s, Me), 3.70 (3H, s, Me), 4.45-4.53 $\left(4 \mathrm{H}, \mathrm{m}, 2 \times \mathrm{ArCH}_{2}\right), 7.14-7.19(4 \mathrm{H}, \mathrm{m}, \mathrm{ArH}), 7.42-7.45(4 \mathrm{H}, \mathrm{m}$, ArH). ${ }^{13} \mathrm{C}$ NMR (125 MHz, $\left.\mathrm{CDCl}_{3}\right) \delta 33.3,41.2,45.1,45.9,46.3$, 52.3, 52.5, 71.8, 72.0, 78.3, 81.9, $121.6(2 \times \mathrm{C}), 129.4(2 \times \mathrm{C})$, $129.6(2 \times \mathrm{C}), 131.5(2 \times \mathrm{C}), 131.6(2 \times \mathrm{C}), 137.4,137.5,173.1$, 174.1. HRMS (ESI, $m / z$ ) for $\mathrm{C}_{25} \mathrm{H}_{26} \mathrm{Br}_{2} \mathrm{O}_{6}[\mathrm{M}+\mathrm{H}]^{+}$calc. 581.0169; found 581.0182 .

Dimethyl 5,6-bis(allyloxy) bicyclo[2.2.1]heptane-3-endo-2exo-dicarboxylate (9i). Compound $9 \mathbf{i}$ was prepared from diol 6 (302 $\mathrm{mg}, 1.24 \mathrm{mmol}$ ) and allyl bromide $(530 \mu \mathrm{L}, 5.70 \mathrm{mmol})$ according to general procedure A (but was stirred for 4 days) and was purified by column chromatography $(20 \%$ EtOAc in pet. spirits) to give the title compound (107 mg, 29\%) as a clear oil; $R_{\mathrm{f}}=0.44$ (20\% EtOAc in pet. spirits). ${ }^{1} \mathrm{H}$ NMR $\left(270 \mathrm{MHz}, \mathrm{CDCl}_{3}\right)$ $\delta 1.41(1 \mathrm{H}, \mathrm{dt}, J=10.6,1.5 \mathrm{~Hz}, \mathrm{H} 7 \mathrm{~s}), 1.99(1 \mathrm{H}, \mathrm{dd}, J=10.7,1.6$ Hz, H7a), 2.58-2.59 (1H, m, H1), 2.64-2.68 (2H, m, H2, H4), 3.18 $(1 \mathrm{H}, \mathrm{dd}, J=5.3,4.8 \mathrm{~Hz}, \mathrm{H} 3), 3.43(1 \mathrm{H}, \mathrm{dd}, J=5.9,1.7 \mathrm{~Hz}, \mathrm{H} 5)$, $3.56(1 \mathrm{H}, \mathrm{dd}, J=5.9,1.6 \mathrm{~Hz}, \mathrm{H} 6), 3.69(3 \mathrm{H}, \mathrm{s}, \mathrm{Me}), 3.70(3 \mathrm{H}, \mathrm{s}$, $\mathrm{Me}), 4.01\left(2 \mathrm{H}, \mathrm{dt}, J=5.6,1.4 \mathrm{~Hz}, \mathrm{OCH}_{2}\right), 4.06(2 \mathrm{H}, \mathrm{dt}, J=5.6,1.4$ $\left.\mathrm{Hz}, \mathrm{OCH}_{2}\right), 5.13-5.31\left(4 \mathrm{H}, \mathrm{m}, 2 \times \mathrm{CH}_{2} \mathrm{CH}\right), 5.81-5.98(2 \mathrm{H}, \mathrm{m}, 2$ $\left.\times \mathrm{CH}_{2} \mathrm{CH}\right) .{ }^{13} \mathrm{C} \mathrm{NMR}\left(67.5 \mathrm{MHz}, \mathrm{CDCl}_{3}\right) \delta 33.3,44.2,45.1,46.0$, 
46.4, 52.2, 52.4, 71.8, 71.9, 78.3, 81.8, $117.1(2 \times \mathrm{C}), 135.0(2 \times$ C), 173.2, 174.3. HRMS (ESI, $m / z$ ) for $\mathrm{C}_{17} \mathrm{H}_{24} \mathrm{O}_{6}[\mathrm{M}+\mathrm{Na}]^{+}$calc. 347.1465 ; found 347.1479 .

\section{General procedure B for the hydrolysis of diesters 9a-i}

A biphasic solution of the appropriate diester $(0.71 \mathrm{mmol}), 2 \mathrm{M}$ $\mathrm{NaOH}(1.5 \mathrm{~mL})$ and THF $(3.0 \mathrm{~mL})$ was stirred at ambient temperature for $16 \mathrm{~h}$. All organic impurities were extracted with $\mathrm{CH}_{2} \mathrm{Cl}_{2}(2 \times 5 \mathrm{~mL})$ and the remaining aqueous phase was acidified using $4 \mathrm{M} \mathrm{HCl}(\mathrm{pH}=1)$ and extracted with EtOAc $(3 \times$ $10 \mathrm{~mL}$ ). The combined organic phase was washed with brine (10 $\mathrm{mL})$, dried $\left(\mathrm{MgSO}_{4}\right)$, filtered and concentrated in vacuo to afford the required diacid.

5,6-Bis(methoxy) bicyclo[2.2.1] heptane-3-endo-2-exo-dicarboxylic acid (12a). The title compound 12a was prepared from diester 9a (194 mg, $0.71 \mathrm{mmol}$ ) according to general procedure $\mathrm{B}$ and isolated as a white waxy solid $(127 \mathrm{mg}, 73 \%) .{ }^{1} \mathrm{H}$ NMR $\left(270 \mathrm{MHz}, \mathrm{CDCl}_{3}\right) \delta 1.43(1 \mathrm{H}, \mathrm{d}, J=10.7 \mathrm{~Hz}, \mathrm{H} 7 \mathrm{~s}), 1.96(1 \mathrm{H}, \mathrm{d}, J$ $=10.0 \mathrm{~Hz}, \mathrm{H} 7 \mathrm{a}), 2.67-2.76(3 \mathrm{H}, \mathrm{m}, \mathrm{H} 1, \mathrm{H} 2, \mathrm{H} 4), 3.25$ (1H, app. t, $J=5.4 \mathrm{~Hz}, \mathrm{H} 3), 3.41$ (3H, s, Me), 3.44 (3H, s, Me), 3.45-3.50 (2H, $\mathrm{m}, \mathrm{H} 5, \mathrm{H} 6) .{ }^{13} \mathrm{C} \mathrm{NMR}\left(67.5 \mathrm{MHz}, \mathrm{CDCl}_{3}\right) \delta 33.1,43.1,44.8,44.9$, $46.3,58.8,58.9,80.8,84.1,178.0,179.2$. HRMS (ESI, $m / z$ ) for $\mathrm{C}_{11} \mathrm{H}_{16} \mathrm{O}_{6}[\mathrm{M}+\mathrm{Cl}]^{-}$calc. 279.0641; found 279.0652 .

5,6-Bis(benzyloxy) bicyclo[2.2.1] heptane-3-endo-2-exo-dicarboxylic acid (12b). The title compound 12b was prepared from diester $\mathbf{9 b}$ (717 mg, $1.69 \mathrm{mmol}$ ) according to general procedure $\mathrm{B}$ and isolated as a white powder (525 mg, 78\%). ${ }^{1} \mathrm{H}$ NMR (270 $\left.\mathrm{MHz} \mathrm{CDCl}_{3}\right) \delta 1.48(1 \mathrm{H}, \mathrm{d}, J=10.9 \mathrm{~Hz}, \mathrm{H} 7 \mathrm{~s}), 2.17(1 \mathrm{H}, \mathrm{d}, J=$ $10.5 \mathrm{~Hz}, \mathrm{H} 7 \mathrm{a}), 2.63$ (1H, d, $J=5.6 \mathrm{~Hz}, \mathrm{H} 1), 2.73$ (1H, br s, H2), $2.79(1 \mathrm{H}, \mathrm{d}, J=4.0 \mathrm{~Hz}, \mathrm{H} 4), 3.23(1 \mathrm{H}$, app. $\mathrm{t}, J=5.4 \mathrm{~Hz}, \mathrm{H} 3), 3.63$ $(2 \mathrm{H}, \mathrm{t}, J=6.4 \mathrm{~Hz}, \mathrm{H} 5, \mathrm{H} 6), 4.57-4.67\left(4 \mathrm{H}, \mathrm{m}, 2 \times \mathrm{ArCH}_{2}\right), 7.23-$ $7.35(10 \mathrm{H}, \mathrm{m}, \mathrm{Ar} H) .{ }^{13} \mathrm{C} \mathrm{NMR}\left(67.5 \mathrm{MHz}, \mathrm{DMSO}-d_{6}\right) \delta 32.9,43.6$, 44.7, 45.3, 46.1, 71.6, 71.7, 78.1, 81.5, $127.4(2 \times \mathrm{C}), 127.7(4 \times$ C), $128.1(2 \times \mathrm{C}), 128.1(2 \times \mathrm{C}), 138.5,138.7,173.6,174.8$. HRMS (ESI, $m / z$ ) for $\mathrm{C}_{23} \mathrm{H}_{24} \mathrm{O}_{6}[\mathrm{M}-\mathrm{H}]^{-}$calc. 395.1501; found 395.1504 .

5,6-Bis(2-methylbenzyloxy) bicyclo[2.2.1]heptane-2-endo-2exo-dicarboxylic acid (12c). The title compound 12c was prepared from diester 9c (121 $\mathrm{mg}, 0.27 \mathrm{mmol})$ according to general procedure B and isolated as a clear oil (113 mg, 99\%). ${ }^{1} \mathrm{H}$ NMR (500 MHz, DMSO- $\left.d_{6}\right) \delta 1.31(1 \mathrm{H}, \mathrm{d}, J=10.1 \mathrm{~Hz}, \mathrm{H} 7 \mathrm{~s})$, 1.85 (1H, d, J=9.4 Hz, H7a), 2.19 (3H, s, Me), 2.21 (3H, s, Me), $2.47(1 \mathrm{H}, \mathrm{d}, J=5.5 \mathrm{~Hz}, \mathrm{H} 4), 2.55(1 \mathrm{H}, \mathrm{br} \mathrm{s}, \mathrm{H} 1), 2.61(1 \mathrm{H}, \mathrm{d}, J=$ $3.3 \mathrm{~Hz}, \mathrm{H} 2), 2.99$ (1H, app. t, $J=5.0 \mathrm{~Hz}, \mathrm{H} 3), 3.59(1 \mathrm{H}, \mathrm{d}, J=5.7$ $\mathrm{Hz}, \mathrm{H} 5), 3.64$ (1H, d, J = 5.6 Hz, H6), 4.44-4.49 (2H, m, $\left.\mathrm{ArCH}_{2}\right)$, $4.53\left(2 \mathrm{H}\right.$, br s, $\left.\mathrm{ArCH}_{2}\right), 7.08-7.18$ (6H, m, ArH) , 7.22-7.27 (2H, m, $\mathrm{ArH}), 12.54(2 \mathrm{H}$, br s, $2 \times \mathrm{COOH}) .{ }^{13} \mathrm{C}$ NMR $(125 \mathrm{MHz}$, DMSO$\left.d_{6}\right) \delta 18.3(2 \times \mathrm{C}), 33.0,43.6,44.7,45.2,46.1,70.0,70.1,78.5$, 81.8, $125.5(2 \times \mathrm{C}), 127.5(2 \times \mathrm{C}), 128.3(2 \times \mathrm{C}), 129.8(2 \times \mathrm{C})$, $136.1(2 \times \mathrm{C}), 136.5,136.6,173.6,174.8$. HRMS (ESI, $m / z)$ for $\mathrm{C}_{25} \mathrm{H}_{28} \mathrm{O}_{6}[\mathrm{M}+\mathrm{Na}]^{+}$calc. 447.1778; found 447.1787.

5,6-Bis[(4-trifluoromethyl)benzyloxy] bicyclo[2.2.1]heptane3-endo-2-exo-dicarboxylic acid (12d). The title compound 12d was prepared from diester $9 \mathrm{~d}$ (423 $\mathrm{mg}, 0.755 \mathrm{mmol}$ ) according to general procedure $\mathrm{B}$ and isolated as a white powder $(316 \mathrm{mg}$, 79\%); m.p: $114.8-143.7{ }^{\circ} \mathrm{C} .{ }^{1} \mathrm{H}$ NMR (500 MHz, DMSO- $\left.d_{6}\right) \delta 1.34$
$(1 \mathrm{H}, \mathrm{d}, J=10.1 \mathrm{~Hz}, \mathrm{H} 7 \mathrm{~s}), 1.90(1 \mathrm{H}, \mathrm{d}, J=9.7 \mathrm{~Hz}, \mathrm{H} 7 \mathrm{a}), 2.48(1 \mathrm{H}$, m, H2), 2.58 (1H, br s, H1), 2.62-2.63 (1H, m, H4), 3.01 (1H, dd, $=5.4,4.8 \mathrm{~Hz}, \mathrm{H} 3), 3.62(1 \mathrm{H}, \mathrm{d}, J=5.6 \mathrm{~Hz}, \mathrm{H} 6), 3.72(1 \mathrm{H}, \mathrm{d}, J=$ $5.5 \mathrm{~Hz}, \mathrm{H} 5), 4.57-4.69\left(4 \mathrm{H}, \mathrm{m}, 2 \times \mathrm{ArCH}_{2}\right), 7.46-7.50(4 \mathrm{H}, \mathrm{m}$, ArH), 7.60-7.63 (4H, m, ArH), 12.58 (2H, br s, $2 \times \mathrm{COOH}) .{ }^{13} \mathrm{C}$ NMR (125 MHz, DMSO- $\left.d_{6}\right) \delta 33.0,43.6,44.6,45.3,46.0,70.7$, $70.8,78.4,81.7,124.4\left(\mathrm{q},{ }^{1} J_{\mathrm{CF}}=270 \mathrm{~Hz}, 2 \times \mathrm{CF}_{3}\right), 124.9\left(\mathrm{q},{ }^{3} J_{\mathrm{CF}}=\right.$ $3.3 \mathrm{~Hz}, 2 \times \mathrm{CH}), 125.0\left(\mathrm{q},{ }^{3} J_{\mathrm{CF}}=3.3 \mathrm{~Hz}, 2 \times \mathrm{CH}\right), 127.83(2 \times \mathrm{C})$, $127.84\left(\mathrm{q},{ }^{2} J_{\mathrm{CF}}=31.6 \mathrm{~Hz}, 2 \times \mathrm{C}\right), 127.9(2 \times \mathrm{C}), 143.5,143.6$, 173.6, 174.8. ${ }^{19} \mathrm{~F}$ NMR (470 MHz, DMSO- $\left.d_{6}\right) \delta-61.43$. HRMS (ESI, $m / z$ ) for $\mathrm{C}_{25} \mathrm{H}_{22} \mathrm{~F}_{6} \mathrm{O}_{6}[\mathrm{M}+\mathrm{Na}]^{+}$calc. 555.1213; found 555.1211 .

5,6-Bis(3-fluorobenzyloxy) bicyclo[2.2.1]heptane-3-endo-2exo-dicarboxylic acid (12e). The title compound 12e was prepared from diester $9 \mathrm{e}(292 \mathrm{mg}, 0.635 \mathrm{mmol})$ according to general procedure $\mathrm{B}$ and isolated as a clear waxy solid $(206 \mathrm{mg}$, $75 \%) .{ }^{1} \mathrm{H}$ NMR (500 MHz, CD 3 OD) $\delta 1.45(1 \mathrm{H}, \mathrm{d}, J=10.5 \mathrm{~Hz}$, H7s), 2.04 (1H, dd, $J=10.5,1.5 \mathrm{~Hz}, \mathrm{H} 7 \mathrm{a}), 2.61$ (1H, dd, $J=5.6$, $0.9 \mathrm{~Hz}, \mathrm{H} 2), 2.65$ (1H, br s, H1), $2.70(1 \mathrm{H}, \mathrm{dd}, J=4.5,1.4 \mathrm{~Hz}, \mathrm{H} 4)$, $3.16(1 \mathrm{H}, \mathrm{dd}, J=5.5,4.8 \mathrm{~Hz}, \mathrm{H} 3), 3.67-3.71$ (2H, m, H5, H6), 4.56 $\left(2 \mathrm{H}, \mathrm{s}, \mathrm{ArCH}_{2}\right), 4.61\left(2 \mathrm{H}, \mathrm{s}, \mathrm{ArCH}_{2}\right), 6.96-7.00(2 \mathrm{H}, \mathrm{m}, \mathrm{ArH})$, 7.04-7.14 (4H, m, ArH), 7.27-7.33 (2H, m, ArH). ${ }^{13} \mathrm{C}$ NMR (125 $\left.\mathrm{MHz}, \mathrm{CD}_{3} \mathrm{OD}\right) \delta 33.9,45.2,46.2,47.2,47.6,73.7\left(\mathrm{~d},{ }^{4} J_{\mathrm{CF}}=1.3\right.$ $\mathrm{Hz}), 72.8\left(\mathrm{~d},{ }^{4} J_{\mathrm{CF}}=1.5 \mathrm{~Hz}\right), 80.0,83.4,115.2\left(\mathrm{~d},{ }^{2} J_{\mathrm{CF}}=21.1 \mathrm{~Hz}\right)$, $115.3\left(\mathrm{~d},{ }^{2} J_{\mathrm{CF}}=21.6 \mathrm{~Hz}\right), 115.4\left(\mathrm{~d},{ }^{2} J_{\mathrm{CF}}=22.3 \mathrm{~Hz}\right), 115.5\left(\mathrm{~d},{ }^{2} J_{\mathrm{CF}}\right.$ $=21.7 \mathrm{~Hz}), 124.4\left(\mathrm{~d},{ }^{3} J_{\mathrm{CF}}=2.7 \mathrm{~Hz}\right), 124.5\left(\mathrm{~d},{ }^{3} J_{\mathrm{CF}}=2.7 \mathrm{~Hz}\right)$, 130.98, 131.04, $142.6\left(\mathrm{~d},{ }^{3} J_{\mathrm{CF}}=7.2 \mathrm{~Hz}\right), 142.7\left(\mathrm{~d},{ }^{3} J_{\mathrm{CF}}=7.2 \mathrm{~Hz}\right)$, $164.26\left(\mathrm{~d},{ }^{1} J_{\mathrm{CF}}=242.9 \mathrm{~Hz}\right), 164.28\left(\mathrm{~d},{ }^{1} J_{\mathrm{CF}}=242.8 \mathrm{~Hz}\right), 175.7$, 176.9. ${ }^{19} \mathrm{~F}$ NMR $\left(470 \mathrm{MHz}, \mathrm{CD}_{3} \mathrm{OD}\right) \delta-116.06,-116.03$. HRMS (ESI, $m / z$ ) for $\mathrm{C}_{23} \mathrm{H}_{22} \mathrm{~F}_{2} \mathrm{O}_{6}[\mathrm{M}+\mathrm{Na}]^{+}$calc. 455.1277; found 455.1264 .

5,6-Bis(4-fluorobenzyloxy) bicyclo[2.2.1]heptane-3-endo-2exo-dicarboxylic acid (12f). The title compound 12f was prepared from diester $9 f(115 \mathrm{mg}, 0.25 \mathrm{mmol})$ according to general procedure $\mathrm{B}$ and isolated as a white powder $(103 \mathrm{mg}$, 94\%); m.p: $198.1-199.5{ }^{\circ} \mathrm{C} .{ }^{1} \mathrm{H}$ NMR (270 MHz, $\left.\mathrm{CDCl}_{3}\right) \delta 1.48$ $(1 \mathrm{H}, \mathrm{d}, J=10.6 \mathrm{~Hz}, \mathrm{H} 7 \mathrm{~s}), 2.13(1 \mathrm{H}, \mathrm{d}, J=10.8 \mathrm{~Hz}, \mathrm{H} 7 \mathrm{a}), 2.64(1 \mathrm{H}$, $\mathrm{d}, J=5.8 \mathrm{~Hz}, \mathrm{H} 2), 2.72(1 \mathrm{H}$, br s, H1), 2.76-2.78 (1H, m, H4), 3.24 (1H, dd, $J=5.7,4.8 \mathrm{~Hz}, \mathrm{H} 3$ ), 3.56-3.64 (2H, m, H5, H6), 4.53 $\left(2 \mathrm{H}, \mathrm{br} \mathrm{s}, \mathrm{ArCH}_{2}\right), 4.56\left(2 \mathrm{H}, \mathrm{br} \mathrm{s}, \mathrm{ArCH}_{2}\right), 6.93-7.02(4 \mathrm{H}, \mathrm{m}, \mathrm{ArH})$, 7.23-7.31 (4H, m, ArH). ${ }^{13} \mathrm{C}$ NMR (67.5 MHz, DMSO- $\left.d_{6}\right) \delta 32.9$, 43.6, 44.6, 45.3, 46.0, 70.8, 70.9, 78.0, 81.4, $114.8\left(\mathrm{~d},{ }^{2} J_{\mathrm{CF}}=21.1\right.$ $\mathrm{Hz}, 2 \times \mathrm{CH}), 114.9\left(\mathrm{~d},{ }^{2} J_{\mathrm{CF}}=21.0 \mathrm{~Hz}, 2 \times \mathrm{CH}\right), 129.6\left(\mathrm{~d},{ }^{3} J_{\mathrm{CF}}=\right.$ $8.0 \mathrm{~Hz}, 2 \times \mathrm{CH}), 129.7\left(\mathrm{~d},{ }^{3} J_{\mathrm{CF}}=8.1 \mathrm{~Hz}, 2 \times \mathrm{CH}\right), 134.7\left(\mathrm{~d},{ }^{4} J_{\mathrm{CF}}=\right.$ $3.0 \mathrm{~Hz}), 134.9\left(\mathrm{~d},{ }^{4} J_{\mathrm{CF}}=3.0 \mathrm{~Hz}\right), 161.5\left(\mathrm{~d},{ }^{1} J_{\mathrm{CF}}=241.3 \mathrm{~Hz}, 2 \times\right.$ $\mathrm{CF}), 173.5,174.7 .{ }^{19} \mathrm{~F}$ NMR (470 MHz, DMSO- $\left.d_{6}\right) \delta-116.68$. HRMS (ESI, $m / z$ ) for $\mathrm{C}_{23} \mathrm{H}_{22} \mathrm{~F}_{2} \mathrm{O}_{6}[\mathrm{M}+\mathrm{Na}]^{+}$calc. 455.1277; found 455.1270 .

5,6-Bis(3-bromobenzyloxy) bicyclo[2.2.1]heptane-3-endo-2exo-dicarboxylic acid (12g). The title compound $12 \mathrm{~g}$ was prepared from diester $9 \mathrm{~g}$ (265 $\mathrm{mg}, 0.455 \mathrm{mmol}$ ) according to general procedure $\mathrm{B}$ and isolated as a white powder $(171 \mathrm{mg}$, 68\%); m.p: 76.0-78.1 ${ }^{\circ} \mathrm{C} .{ }^{1} \mathrm{H}$ NMR $\left(270 \mathrm{MHz}, \mathrm{CDCl}_{3}\right) \delta 1.50(1 \mathrm{H}$, $\mathrm{d}, J=11.3 \mathrm{~Hz}, \mathrm{H} 7 \mathrm{~s}), 2.16(1 \mathrm{H}, \mathrm{d}, J=11.1 \mathrm{~Hz}, \mathrm{H} 7 \mathrm{a}), 2.67(1 \mathrm{H}, \mathrm{d}, J$ $=4.9 \mathrm{~Hz}, \mathrm{H} 2), 2.75(1 \mathrm{H}, \mathrm{br} \mathrm{s}, \mathrm{H} 1), 2.79(1 \mathrm{H}, \mathrm{d}, J=4.3 \mathrm{~Hz}, \mathrm{H} 4)$, 3.27 (1H, app. t, $J=5.6 \mathrm{~Hz}, \mathrm{H} 3$ ), 3.62-3.67 (2H, m, H5, H6), 4.55 $\left(2 \mathrm{H}, \mathrm{s}, \mathrm{ArCH}_{2}\right), 4.58\left(2 \mathrm{H}, \mathrm{s}, \mathrm{ArCH}_{2}\right), 7.14-7.24(4 \mathrm{H}, \mathrm{m}, \mathrm{ArH}), 7.36-$ 
$7.49(4 \mathrm{H}, \mathrm{m}, \mathrm{Ar} H) .{ }^{13} \mathrm{C} \mathrm{NMR}\left(67.5 \mathrm{MHz}, \mathrm{CDCl}_{3}\right) \delta 33.5,43.9,44.9$, 45.9, 46.2, 71.9, 72.0, 78.5, 81.9, 122.6, 122.7, 126.2, 126.4, 130.1, 130.2, 130.7, 130.8, 130.9 ( $2 \times \mathrm{C}), 140.5,140.6,177.5,178.6$. HRMS (ESI, $m / z$ ) for $\mathrm{C}_{23} \mathrm{H}_{22} \mathrm{Br}_{2} \mathrm{O}_{6}[\mathrm{M}-\mathrm{H}]^{-}$calc. 550.9710; found 550.9729 .

5,6-Bis(4-bromobenzyloxy) bicyclo[2.2.1]heptane-3-endo-2exo-dicarboxylic acid (12h). The title compound 12h was prepared from diester $\mathbf{9 h}$ (159 $\mathrm{mg}, 0.273 \mathrm{mmol}$ ) according to general procedure $\mathrm{B}$ and isolated as a white powder $(119 \mathrm{mg}$, 79\%); m.p: $119.7-124.9{ }^{\circ} \mathrm{C} .{ }^{1} \mathrm{H}$ NMR (500 MHz, CD $\left.{ }_{3} \mathrm{OD}\right) \delta 1.43$ $(1 \mathrm{H}, \mathrm{d}, J=10.4 \mathrm{~Hz}, \mathrm{H} 7 \mathrm{~s}), 2.02(1 \mathrm{H}, \mathrm{dd}, J=10.4,1.1 \mathrm{~Hz}, \mathrm{H} 7 \mathrm{a})$, $2.60(1 \mathrm{H}, \mathrm{d}, J=5.4 \mathrm{~Hz}, \mathrm{H} 2), 2.63(1 \mathrm{H}, \mathrm{br} \mathrm{s}, \mathrm{H} 1), 2.68$ (1H, dd, $J=$ $4.5,1.3 \mathrm{~Hz}, \mathrm{H} 4), 3.15$ (1H, app. $\mathrm{t}, J=5.4 \mathrm{~Hz}, \mathrm{H} 3), 3.65-3.68(2 \mathrm{H}$, $\mathrm{m}, \mathrm{H} 5, \mathrm{H} 6), 4.50\left(2 \mathrm{H}, \mathrm{m}, \mathrm{ArCH}_{2}\right), 4.54-4.56\left(2 \mathrm{H}, \mathrm{m}, \mathrm{ArCH}_{2}\right)$, 7.19-7.24 (4H, m, ArH), 7.42-7.44 (4H, m, ArH). ${ }^{13} \mathrm{C}$ NMR (125 $\left.\mathrm{MHz}, \mathrm{CD}_{3} \mathrm{OD}\right) \delta 33.9,45.2,46.2,47.2,47.6,72.7,72.8,79.8,83.3$, 122.3, 122.4, $130.8(2 \times \mathrm{C}), 130.9(2 \times \mathrm{C}), 132.4(4 \times \mathrm{C}), 138.9$, 139.1, 173.6, 174.8. HRMS (ESI, $m / z$ ) for $\mathrm{C}_{23} \mathrm{H}_{22} \mathrm{Br}_{2} \mathrm{O}_{6}[\mathrm{M}-\mathrm{H}]^{-}$ calc. 550.9710; found 550.9723 .

5,6-Bis(allyloxy) bicyclo[2.2.1] heptane-3-endo-2-exo-dicarboxylic acid (12i). The title compound $12 \mathbf{i}$ was prepared from diester $9 \mathbf{i}$ ( $41 \mathrm{mg}, 0.127 \mathrm{mmol}$ ) according to general procedure B and isolated as a viscous yellow oil $(127 \mathrm{mg}, 73 \%) .{ }^{1} \mathrm{H}$ NMR $(270$ $\left.\mathrm{MHz} \mathrm{CDCl}_{3}\right) \delta$ 1.41-1.45 (1H, m, H7s), $2.04(1 \mathrm{H}, \mathrm{d}, J=10.4 \mathrm{~Hz}$, H7a), 2.64-2.72 (3H, m, H1, H2, H4), $3.22(1 \mathrm{H}, \mathrm{dd}, J=5.5,4.7$ $\mathrm{Hz}, \mathrm{H} 3), 3.56-3.61$ (2H, m, H5, H6), 4.03-4.10 (4H, m, $2 \times$ $\left.\mathrm{OCH}_{2}\right), 5.12-5.32\left(4 \mathrm{H}, \mathrm{m}, 2 \times \mathrm{CH}_{2} \mathrm{CH}\right), 5.82-5.99(2 \mathrm{H}, \mathrm{m}$, $\left.\mathrm{CH}_{2} \mathrm{CH}\right) .{ }^{13} \mathrm{C} \mathrm{NMR}\left(125 \mathrm{MHz}, \mathrm{CDCl}_{3}\right) \delta 33.2,43.9,44.9,45.8$, 46.2, 71.7, 71.8, 78.2, 81.6, 117.2, 117.3, 134.6, 134.7, 178.1, 179.2. HRMS (ESI, $m / z$ ) for $\mathrm{C}_{15} \mathrm{H}_{20} \mathrm{O}_{6}[\mathrm{M}+\mathrm{Na}]^{+}$calc. 319.1152; found 319.1152 .

\section{General procedure $\mathrm{C}$ for the amidation of diacids $12 \mathrm{a}-\mathbf{i}$}

A microwave vial was charged with the appropriate carboxylic acid, EDCI (3.0 equiv.), HOBt (0.1 equiv.) and dry DMF and was stirred at ambient temperature for $30 \mathrm{~min}$. Aminoethylguanidine 14 (3.0 equiv.) was then added and the reaction was irradiated to $50{ }^{\circ} \mathrm{C}$ for $30 \mathrm{~min}$. The resulting homogenous clear mixture was diluted with EtOAc $(15 \mathrm{~mL})$, washed with $\mathrm{H}_{2} \mathrm{O}$ $(3 \times 8 \mathrm{~mL})$, brine $(8 \mathrm{~mL})$, dried $\left(\mathrm{MgSO}_{4}\right)$, filtered, and concentrated in vacuo to afford a solid that was purified by column chromatography (as specified below) to give the title compound.

3-endo-2-exo-Di[ $2^{\prime}$-(2", $3^{\prime \prime}$-di-tert-butoxycarbonylguanidino)ethylcarbamoyl]-5,6-bis(methoxy)bicyclo[2.2.1]heptane (15a). Compound 15a was prepared from diacid 12a (96 mg, 0.39 $\mathrm{mmol}$ ) and amine 14 (357 $\mathrm{mg}, 1.18 \mathrm{mmol}$ ) according to general procedure $\mathrm{C}$ and after purification by column chromatography (EtOAc) was isolated as a clear oil (230 mg, 72\%); $R_{\mathrm{f}}=0.25$ (EtOAc). ${ }^{1} \mathrm{H}$ NMR $\left(500 \mathrm{MHz}, \mathrm{CDCl}_{3}\right) \delta 1.45-1.47(36 \mathrm{H}, \mathrm{m}, 4 \times t$ $\mathrm{Bu}), 1.56(1 \mathrm{H}, \mathrm{d}, J=10.2 \mathrm{~Hz}, \mathrm{H} 7 \mathrm{a}), 1.89(1 \mathrm{H}, \mathrm{d}, J=10.2 \mathrm{~Hz}, \mathrm{H} 7 \mathrm{~s})$, $2.45(1 \mathrm{H}, \mathrm{d}, J=6.3 \mathrm{~Hz}, \mathrm{H} 2), 2.56(1 \mathrm{H}, \mathrm{br} \mathrm{s}, \mathrm{H} 1), 2.68(1 \mathrm{H}, \mathrm{br} \mathrm{s}$, H4), $2.82(1 \mathrm{H}$, app. t, $J=5.3 \mathrm{~Hz}, \mathrm{H} 3), 3.34(3 \mathrm{H}, \mathrm{s}, \mathrm{OMe}), 3.36(3 \mathrm{H}$, s, OMe), 3.38-3.60 (10H, m, $\left.4 \times \mathrm{CH}_{2}, \mathrm{H} 5, \mathrm{H} 6\right), 6.69(1 \mathrm{H}, \mathrm{t}, J=5.4$ $\mathrm{Hz}, \mathrm{NH}), 8.02(1 \mathrm{H}, \mathrm{t}, J=3.4 \mathrm{~Hz}, \mathrm{NH}), 8.45(1 \mathrm{H}, \mathrm{t}, J=5.5 \mathrm{~Hz}, \mathrm{NH})$, $8.65(1 \mathrm{H}, \mathrm{t}, J=5.6 \mathrm{~Hz}, \mathrm{NH}), 11.44(1 \mathrm{H}, \mathrm{s}, \mathrm{NH}), 11.48(1 \mathrm{H}, \mathrm{s}, \mathrm{NH})$. ${ }^{13} \mathrm{C}$ NMR $\left(125 \mathrm{MHz}, \mathrm{CDCl}_{3}\right) \delta 28.1,28.2,28.3,28.4,33.8,39.4$,
39.8, 40.1, 40.3, 42.4, 42.9, 43.7, 45.0, 49.3, 58.4, 58.6, 79.5, 80.0, $81.1,83.3,83.8,84.2,153.1,153.2,156.8,157.9,163.0,163.5$, 172.3, 174.4. HRMS (ESI, $m / z$ ) for $\mathrm{C}_{37} \mathrm{H}_{64} \mathrm{~N}_{8} \mathrm{O}_{12}[\mathrm{M}+\mathrm{H}]^{+}$calc. 813.4717; found 813.4733.

3-endo-2-exo-Di[ $2^{\prime}-\left(2^{\prime \prime}, 3^{\prime \prime}\right.$-di-tert-butoxycarbonylguanidino)ethylcarbamoyl]-5,6-bis(2-methylbenzyloxy)bicyclo[2.2.1] heptane (15c). Compound 15c was prepared from diacid 12c (62 mg, 0.15 $\mathrm{mmol}$ ) and amine 14 (140 $\mathrm{mg}, 0.45 \mathrm{mmol}$ ) according to general procedure $\mathrm{C}$ and after purification by column chromatography (50-70\% EtOAc in pet. spirits) was isolated as a white solid (36 $\mathrm{mg}, 54 \%) ; R_{\mathrm{f}}=0.71$ (70\% EtOAc in pet. spirits); m.p: 117.7-120.7 ${ }^{\circ} \mathrm{C} .{ }^{1} \mathrm{H}$ NMR $\left(500 \mathrm{MHz}, \mathrm{CDCl}_{3}\right) \delta 1.46-1.48(36 \mathrm{H}, \mathrm{m}, 4 \times t$-Bu), $1.63(1 \mathrm{H}, \mathrm{d}, J=10.2 \mathrm{~Hz}, \mathrm{H} 7 \mathrm{~s}), 2.12(1 \mathrm{H}, \mathrm{d}, J=9.3, \mathrm{~Hz}, \mathrm{H} 7 \mathrm{a}), 2.25$ (3H, s, ArMe), 2.27 (3H, s, ArMe), 2.48 (1H, d, J=6.2 Hz, H2), 2.60 (1H, br s, H1), $2.73(1 \mathrm{H}, \mathrm{d}, J=3.1 \mathrm{~Hz}, \mathrm{H} 4), 2.82(1 \mathrm{H}$, app. t, $J=4.7$ $\mathrm{Hz}, \mathrm{H} 3), 3.23-3.55\left(8 \mathrm{H}, \mathrm{m}, 4 \times \mathrm{CH}_{2}\right), 3.58(1 \mathrm{H}, \mathrm{d}, J=5.5 \mathrm{~Hz}, \mathrm{H} 5)$, $3.61(1 \mathrm{H}, \mathrm{d}, J=5.8 \mathrm{~Hz}, \mathrm{H} 9), 4.50-4.58\left(4 \mathrm{H}, \mathrm{m}, 2 \times \mathrm{CH}_{2} \mathrm{Ar}\right), 6.52$ (1H, br s, NH), 7.08-7.19 (6H, m, ArH), 7.27-7.31 (2H, m, ArH), $8.00(1 \mathrm{H}, \mathrm{t}, J=4.1 \mathrm{~Hz}, \mathrm{NH}), 8.48(1 \mathrm{H}, \mathrm{br} \mathrm{s}, \mathrm{NH}), 8.67(1 \mathrm{H}, \mathrm{t}, J=5.6$ $\mathrm{Hz}, \mathrm{NH}), 11.45$ (1H, s, NH), $11.50(1 \mathrm{H}, \mathrm{s}, \mathrm{NH}) .{ }^{13} \mathrm{C} \mathrm{NMR}(125 \mathrm{MHz}$, $\left.\mathrm{CDCl}_{3}\right) \delta 18.9,19.0,28.1,28.2,28.40,28.42,34.4,39.2$, 40.3, 40.5, 42.3, 44.1, 44.7, 45.2, 49.5, 70.8, 70.9, 78.7, 79.6, 80.2, 82.1, 83.4, 83.8, 125.7, 125.8, 127.6, 127.8, 128.7, 128.9, 130.1, 130.2, 136.6, 136.67, 136.69, 136.8, 153.19, 153.23, 156.7, 157.9, 172.3, 174.6. HRMS (ESI, $m / z$ ) for $\mathrm{C}_{51} \mathrm{H}_{76} \mathrm{~N}_{8} \mathrm{O}_{12}[\mathrm{M}+\mathrm{H}]^{+}$calc. 993.5655; found 993.5654.

3-endo-2-exo-Di $\left[2^{\prime}-\left(2^{\prime \prime}, 3^{\prime \prime}\right.\right.$-di-tert-butoxycarbonylguanidino)ethylcarbamoyl]-5,6-bis[(4-trifluoromethyl)benzyloxy]bicyclo[2.2.1] heptane (15d). Compound 15d was prepared from diacid 12d (151 mg, $0.28 \mathrm{mmol}$ ) and amine 14 (260 mg, $0.85 \mathrm{mmol})$ according to general procedure $\mathrm{C}$ and after purification by flash column chromatography (EtOAc) was isolated as a clear oil (174 $\mathrm{mg}, 56 \%) ; R_{\mathrm{f}}=0.45$ (EtOAc). ${ }^{1} \mathrm{H}$ NMR $\left(500 \mathrm{MHz}, \mathrm{CDCl}_{3}\right) \delta 1.44-$ $1.52(36 \mathrm{H}, \mathrm{m}, 4 \times t-\mathrm{Bu}), 1.68(1 \mathrm{H}, \mathrm{d}, J=10.3 \mathrm{~Hz}, \mathrm{H} 7 \mathrm{~s}), 2.13(1 \mathrm{H}$, $\mathrm{d}, J=9.3 \mathrm{~Hz}, \mathrm{H} 7 \mathrm{a}), 2.48(1 \mathrm{H}, \mathrm{d}, J=6.0 \mathrm{~Hz}, \mathrm{H} 2), 2.65(1 \mathrm{H}$, br s, H1), 2.79-2.80 (1H, m, H4), $2.85(1 \mathrm{H}, \mathrm{dd}, J=5.7,4.5 \mathrm{~Hz}, \mathrm{H} 3)$, 3.23-3.56 (8H, m, $\left.4 \times \mathrm{CH}_{2}\right), 3.58(1 \mathrm{H}, \mathrm{d}, J=6.1 \mathrm{~Hz}, \mathrm{H} 5), 3.62$ $(1 \mathrm{H}, \mathrm{dd}, J=5.8,1.2 \mathrm{~Hz}, \mathrm{H} 9), 4.55-4.67\left(4 \mathrm{H}, \mathrm{m}, 2 \times \mathrm{CH}_{2} \mathrm{Ar}\right), 6.68$ (1H, m, NH), 7.38-7.40 (4H, m, ArH), 7.51-7.54 (4H, m, ArH), $8.16(1 \mathrm{H}, \mathrm{t}, J=4.0 \mathrm{~Hz}, \mathrm{NH}), 8.49(1 \mathrm{H}, \mathrm{m}, \mathrm{NH}), 8.72(1 \mathrm{H}, \mathrm{t}, J=6.0$ $\mathrm{Hz}, \mathrm{NH}), 11.48$ (1H, s, NH), 11.53 (1H, s, NH). ${ }^{13} \mathrm{C}$ NMR (125 $\left.\mathrm{MHz}, \mathrm{CDCl}_{3}\right) \delta 28.1,28.2,28.4,34.3,39.4,40.1,40.4,42.5,43.8$, 44.6, 45.1, 49.4, 71.5, 71.6, 78.9, 79.7, 80.3, 82.1, 83.5, 84.0, 125.3 $\left(\mathrm{q},{ }^{3} J_{\mathrm{CF}}=3.5 \mathrm{~Hz}, 4 \times \mathrm{CH}\right), 126.4\left(\mathrm{q},{ }^{1} J_{\mathrm{CF}}=270 \mathrm{~Hz}, 2 \times \mathrm{CF}_{3}\right)$, $127.66(2 \times \mathrm{C}), 127.72(2 \times \mathrm{C}), 129.7\left(\mathrm{q},{ }^{2} J_{\mathrm{CF}}=32.6 \mathrm{~Hz}\right), 129.8(\mathrm{q}$, $\left.{ }^{2} J_{\mathrm{CF}}=32.6 \mathrm{~Hz}\right), 142.7,142.8,153.2(2 \times \mathrm{C}), 156.7,158.1,163.0$, 163.4, 172.2, 174.3. ${ }^{19} \mathrm{~F}$ NMR $\left(470 \mathrm{MHz}, \mathrm{CDCl}_{3}\right) \delta-62.97$. HRMS (ESI, $m / z$ ) for $\mathrm{C}_{51} \mathrm{H}_{70} \mathrm{~F}_{6} \mathrm{~N}_{8} \mathrm{O}_{12}[\mathrm{M}+\mathrm{H}]^{+}$calc. 1101.5090; found 1101.5110.

3-endo-2-exo- $\mathrm{Di}\left[2^{\prime}-\left(2^{\prime \prime}, 3^{\prime \prime}\right.\right.$-di-tert-butoxycarbonylguanidino)ethylcarbamoyl]-5,6-bis(3-fluorobenzyloxy)bicyclo[2.2.1] heptane (15e). Compound 15e was prepared from diacid 12e (184 mg, $0.43 \mathrm{mmol}$ ) and amine $14(290 \mathrm{mg}, 1.28 \mathrm{mmol})$ according to general procedure $\mathrm{C}$ and after purification by column chromatography (50-70\% EtOAc in pet. spirits) was isolated as a white solid (111 mg, 26\%); $R_{\mathrm{f}}=0.58$ (70\% EtOAc in pet. spirits); m.p: 214.5-258.2 ${ }^{\circ} \mathrm{C}$ (slow decomposition). ${ }^{1} \mathrm{H} \mathrm{NMR}\left(500 \mathrm{MHz}, \mathrm{CDCl}_{3}\right.$ ) 
$\delta$ 1.46-1.49 (36H, m, $4 \times t$-Bu), $1.66(1 \mathrm{H}, \mathrm{d}, J=10.3 \mathrm{~Hz}, \mathrm{H} 7 \mathrm{~s})$, $2.12(1 \mathrm{H}, \mathrm{d}, J=9.3 \mathrm{~Hz}, \mathrm{H7a}), 2.47(1 \mathrm{H}, \mathrm{d}, J=6.1 \mathrm{~Hz}, \mathrm{H} 1), 2.63$ (1H, br s, H4), 2.78-2.79 (1H, m, H1), $2.84(1 \mathrm{H}$, app. t, $J=6.0 \mathrm{~Hz}$, H3), 3.25-3.60 (10H, m, $\left.4 \times \mathrm{CH}_{2}, \mathrm{H} 5, \mathrm{H} 6\right), 4.51-4.61(4 \mathrm{H}, \mathrm{m}, 2 \times$ $\left.\mathrm{CH}_{2} \mathrm{Ar}\right), 6.62(1 \mathrm{H}$, br s, NH), 6.91-7.07 (6H, m, ArH), 7.22-7.28 $(2 \mathrm{H}, \mathrm{m}, \mathrm{ArH}), 8.15(1 \mathrm{H}, \mathrm{t}, J=4.0 \mathrm{~Hz}, \mathrm{NH}), 8.50(1 \mathrm{H}, \mathrm{br} \mathrm{s}, \mathrm{NH})$, $8.72\left(1 \mathrm{H}\right.$, br s, NH) $11.47(1 \mathrm{H}, \mathrm{s}, \mathrm{NH}), 11.53(1 \mathrm{H}, \mathrm{s}, \mathrm{NH}) .{ }^{13} \mathrm{C} \mathrm{NMR}$ $\left(125 \mathrm{MHz}, \mathrm{CDCl}_{3}\right) \delta 28.1,28.2,28.4,34.3,39.3,40.2,40.6,42.4$, 43.7, 44.7, 45.1, 49.4, 71.5, 71.6, 78.5, 80.0, 80.4, 81.9, 83.6, 84.0, $114.3\left(\mathrm{~d},{ }^{2} J_{\mathrm{CF}}=21.4 \mathrm{~Hz}\right), 114.4\left(\mathrm{~d},{ }^{2} J_{\mathrm{CF}}=21.1 \mathrm{~Hz}\right), 114.5\left(\mathrm{~d},{ }^{2} J_{\mathrm{CF}}=\right.$ $21.2 \mathrm{~Hz}), 114.6\left(\mathrm{~d},{ }^{2} J_{\mathrm{CF}}=21.4 \mathrm{~Hz}\right), 123.07\left(\mathrm{~d},{ }^{3} J_{\mathrm{CF}}=2.8 \mathrm{~Hz}\right)$, $123.16\left(\mathrm{~d},{ }^{3} J_{\mathrm{CF}}=2.9 \mathrm{~Hz}\right), 129.8,129.9,141.3\left(\mathrm{~d},{ }^{3} J_{\mathrm{CF}}=7.0 \mathrm{~Hz}\right)$, $141.4\left(\mathrm{~d},{ }^{3} J_{\mathrm{CF}}=7.1 \mathrm{~Hz}\right), 153.1,153.2,156.6,158.0,162.71,162.73$, $162.96\left(\mathrm{~d},{ }^{1} J_{\mathrm{CF}}=244.0 \mathrm{~Hz}\right), 163.02\left(\mathrm{~d},{ }^{1} J_{\mathrm{CF}}=244.0 \mathrm{~Hz}\right), 172.3$, 174.5. ${ }^{19} \mathrm{~F}$ NMR $\left(470 \mathrm{MHz}, \mathrm{CDCl}_{3}\right) \delta-113.92,-113.86$. HRMS (ESI, $m / z$ ) for $\mathrm{C}_{49} \mathrm{H}_{70} \mathrm{~F}_{2} \mathrm{~N}_{8} \mathrm{O}_{12}[\mathrm{M}+\mathrm{H}]^{+}$calc. 1001.5154; found 1001.5165 .

3-endo-2-exo-Di[ $2^{\prime}$-(2", $3^{\prime \prime}$-di-tert-butoxycarbonylguanidino)ethylcarbamoyl]-5,6-bis(4-bromobenzyloxy)bicyclo[2.2.1]heptane (15h). Compound 15h was prepared from diacid 12h (171 mg, $0.31 \mathrm{mmol}$ ) and amine $14(281 \mathrm{mg}, 0.93 \mathrm{mmol})$ according to general procedure $\mathrm{C}$ and after purification by column chromatography (50-70\% EtOAc in pet. spirits) was isolated as a clear oil (91 mg, 26\%); $R_{\mathrm{f}}=0.48$ (70\% EtOAc in pet. spirits). ${ }^{1} \mathrm{H}$ NMR $\left(500 \mathrm{MHz}, \mathrm{CDCl}_{3}\right) \delta 1.46-1.48(36 \mathrm{H}, \mathrm{m}, 4 \times t-\mathrm{Bu}), 1.64(1 \mathrm{H}, \mathrm{d}, J=$ $10.3 \mathrm{~Hz}, \mathrm{H} 7 \mathrm{~s}), 2.09$ (1H, d, $J=9.4 \mathrm{~Hz}, \mathrm{H7a}), 2.46(1 \mathrm{H}, \mathrm{d}, J=6.1$ Hz, H1), 2.60 (1H, br s, H4), 2.74 (1H, m, H2), 2.83 (1H, app. t, $J$ $=4.6 \mathrm{~Hz}, \mathrm{H} 3), 3.22-3.46\left(4 \mathrm{H}, \mathrm{m}, 2 \times \mathrm{CH}_{2}\right), 3.52-3.58(6 \mathrm{H}, \mathrm{m}, 2$ $\left.\times \mathrm{CH}_{2}, \mathrm{H} 5, \mathrm{H} 6\right), 4.46-4.55\left(4 \mathrm{H}, \mathrm{m}, 2 \times \mathrm{CH}_{2} \mathrm{Ar}\right), 6.69(1 \mathrm{H}, \mathrm{m}$, $\mathrm{NH}), 7.14-7.17$ (4H, m, ArH), 7.39-7.42 (4H, m, ArH), $8.09(1 \mathrm{H}, \mathrm{t}$, $J=4.0 \mathrm{~Hz}, \mathrm{NH}), 8.54(1 \mathrm{H}, \mathrm{m}, \mathrm{NH}), 8.73(1 \mathrm{H}, \mathrm{t}, J=5.1 \mathrm{~Hz}, \mathrm{NH})$, 11.47 (1H, s, NH), $11.51(1 \mathrm{H}, \mathrm{s}, \mathrm{NH}) .{ }^{13} \mathrm{C} \mathrm{NMR}\left(125 \mathrm{MHz}, \mathrm{CDCl}_{3}\right)$ $\delta 28.1,28.2,28.4,34.3,39.3,40.2,40.5,42.4,43.8,44.6,45.1$, $49.4,71.56,71.61,78.6,80.0,80.4,81.8,83.6,84.0,121.4,121.5$, $129.5(2 \times \mathrm{C}), 129.6(2 \times \mathrm{C}), 131.4(2 \times \mathrm{C}), 131.5(2 \times \mathrm{C}), \mathbf{1 3 7 . 6}$, $137.7,153.1,153.2,156.7,158.0,162.8,163.2$, 172.2, 174.4 . HRMS (ESI, $m / z$ ) for $\mathrm{C}_{49} \mathrm{H}_{70} \mathrm{Br}_{2} \mathrm{~N}_{8} \mathrm{O}_{12}[\mathrm{M}+\mathrm{H}]^{+}$calc. 1121.3553; found 1121.3550 .

3-endo-2-exo-Di[ $2^{\prime}$-( $2^{\prime \prime}, 3^{\prime \prime}$-di-tert-butoxycarbonylguanidino)ethylcarbamoyl]-5,6-bis(allyloxy)bicyclo[2.2.1] heptane (15i). Compound 15i was prepared from diacid 12i $(70 \mathrm{mg}, 0.24$ $\mathrm{mmol})$ and amine $14(214 \mathrm{mg}, 0.71 \mathrm{mmol})$ according to general procedure $\mathrm{C}$ and after purification by column chromatography (50-70\% EtOAc in pet. spirits) was isolated as a clear oil (128 $\mathrm{mg}, 63 \%) ; R_{\mathrm{f}}=0.34$ (70\% EtOAc in pet. spirits). ${ }^{1} \mathrm{H}$ NMR (500 $\left.\mathrm{MHz}, \mathrm{CDCl}_{3}\right) \delta 1.49-1.50(36 \mathrm{H}, \mathrm{m}, 4 \times t-\mathrm{Bu}), 1.60(1 \mathrm{H}, \mathrm{d}, J=10.3$ $\mathrm{Hz}, \mathrm{H} 7 \mathrm{~s}), 2.02(1 \mathrm{H}, \mathrm{d}, J=10.0 \mathrm{~Hz}, \mathrm{H7a}), 2.48(1 \mathrm{H}, \mathrm{d}, J=6.2 \mathrm{~Hz}$, H4), 2.54 (1H, br s, H1), $2.66(1 \mathrm{H}, \mathrm{d}, J=2.9 \mathrm{~Hz}, \mathrm{H} 2), 2.82(1 \mathrm{H}$, $\mathrm{dd}, J=6.0,4.6 \mathrm{~Hz}, \mathrm{H} 3), 3.33-3.60\left(10 \mathrm{H}, \mathrm{m}, 4 \times \mathrm{CH}_{2}, \mathrm{H} 5, \mathrm{H} 6\right)$, 3.98-4.04 (4H, m, $\left.2 \times \mathrm{OCH}_{2}\right), 5.10-5.14\left(2 \mathrm{H}, \mathrm{m}, \mathrm{CH}_{2} \mathrm{CH}\right), 5.20-$ $5.27\left(2 \mathrm{H}, \mathrm{m}, \mathrm{CH}_{2} \mathrm{CH}\right), 5.84-5.94\left(2 \mathrm{H}, \mathrm{m}, 2 \times \mathrm{CH}_{2} \mathrm{CH}\right), 6.58(1 \mathrm{H}, \mathrm{t}$, $J=5.1 \mathrm{~Hz}, \mathrm{NH}), 8.03(1 \mathrm{H}, \mathrm{t}, J=3.9 \mathrm{~Hz}, \mathrm{NH}), 8.48(1 \mathrm{H}$, br s, NH$)$, $8.68(1 \mathrm{H}, \mathrm{t}, J=5.8 \mathrm{~Hz}, \mathrm{NH}), 11.46(1 \mathrm{H}, \mathrm{s}, \mathrm{NH}), 11.50(1 \mathrm{H}, \mathrm{s}, \mathrm{NH})$. ${ }^{13} \mathrm{C}$ NMR $\left(125 \mathrm{MHz}, \mathrm{CDCl}_{3}\right) \delta 28.17,28.21,28.41,28.44,34.2$, 39.3, 40.2, 40.5, 42.5, 43.9, 44.9, 45.2, 49.4, 71.6, 71.7, 78.6, 80.2, $81.9,83.4,83.9(2 \times \mathrm{C}), 116.6,116.9,135.2,135.3,153.23$,
153.34, 156.7, 158.0, 172.4, 174.6. HRMS (ESI, $m / z$ ) for $\mathrm{C}_{41} \mathrm{H}_{68} \mathrm{~N}_{8} \mathrm{O}_{12}[\mathrm{M}+\mathrm{H}]^{+}$calc. 865.5030; found 865.5027.

\section{General procedure $D$ for the amidation of diacids $12 a-i$}

A microwave vial was charged with the appropriate carboxylic acid, EDCI (3.0 equiv.), HOBt (0.1 equiv.) and dry $\mathrm{CHCl}_{3}$ and was stirred at ambient temperature for $30 \mathrm{~min}$. Aminoethylguanidine 14 (3.0 equiv.) was then added and the reaction was irradiated to $50{ }^{\circ} \mathrm{C}$ for $30 \mathrm{~min}$. The resulting homogenous clear mixture was diluted with $\mathrm{CHCl}_{3}(20 \mathrm{~mL})$, washed with $\mathrm{H}_{2} \mathrm{O}$ $(2 \times 10 \mathrm{~mL})$, brine $(8 \mathrm{~mL})$, dried $\left(\mathrm{MgSO}_{4}\right)$, filtered, and concentrated in vacuo to afford the crude material that was purified by column chromatography (as specified below) to give the title compound.

3-endo-2-exo-Di[ $2^{\prime}$-(2 $2^{\prime \prime}, 3^{\prime \prime}$-di-tert-butoxycarbonylguanidino)ethylcarbamoyl]-5,6-bis(benzyloxy)bicyclo[2.2.1]heptane (15b). Compound 15b was prepared from diacid 12b (343 mg, 0.87 $\mathrm{mmol}$ ) and amine 14 (786 mg, $2.60 \mathrm{mmol}$ ) according to general procedure $\mathrm{D}$ and after purification by column chromatography (70\% EtOAc in pet. spirits) was isolated as a clear oil (563 mg, $57 \%) ; R_{\mathrm{f}}=0.43$ (70\% EtOAc in pet. spirits). ${ }^{1} \mathrm{H}$ NMR $(270 \mathrm{MHz}$, $\left.\mathrm{CDCl}_{3}\right) \delta 1.45-1.49(36 \mathrm{H}, \mathrm{m}, 4 \times t-\mathrm{Bu}), 1.63(1 \mathrm{H}, \mathrm{d}, J=10.8 \mathrm{~Hz}$, H7s), $2.12(1 \mathrm{H}, \mathrm{d}, J=10.4 \mathrm{~Hz}, \mathrm{H} 7 \mathrm{a}), 2.43$ (1H, d, $J=6.2 \mathrm{~Hz}, \mathrm{H} 2)$, 2.60 (1H, s, H1), 2.74-2.76 (1H, m, H4), 2.79-2.83 (1H, m, H3), 3.16-3.57 (10H, m, $\left.4 \times \mathrm{CH}_{2}, \mathrm{H} 5, \mathrm{H} 6\right), 4.55$ (2H, s, $\left.\mathrm{CH}_{2} \mathrm{Ar}\right), 4.59$ $\left(2 \mathrm{H}, \mathrm{s}, \mathrm{CH}_{2} \mathrm{Ar}\right), 6.56(1 \mathrm{H}, \mathrm{t}, J=5.8 \mathrm{~Hz}, \mathrm{NH}), 7.22-7.33(10 \mathrm{H}, \mathrm{m}$, ArH), 7.99 (1H, t, $J=4.0 \mathrm{~Hz}, \mathrm{NH}), 8.45(1 \mathrm{H}, \mathrm{t}, J=5.6 \mathrm{~Hz}, \mathrm{NH})$, $8.69(1 \mathrm{H}, \mathrm{t}, J=4.0 \mathrm{~Hz}, \mathrm{NH}), 11.45(1 \mathrm{H}, \mathrm{s}, \mathrm{NH}), 11.53(1 \mathrm{H}, \mathrm{s}, \mathrm{NH})$. ${ }^{13} \mathrm{C}$ NMR $\left(67.5 \mathrm{MHz}, \mathrm{CDCl}_{3}\right) \delta 28.1,28.2,28.4,34.4,39.2,40.1$, 40.4, 42.5, 43.8, 44.6, 45.1, 49.5, 72.2, 72.3, 78.3, 79.5, 80.1, 81.6, 83.3, 83.8, 127.5, 127.6, 127.8, 128.1, 128.3, 128.4, 138.6, 138.7, 153.2, 156.7, 158.0, 163.1, 163.6, 172.3, 174.5. HRMS (ESI, $m / z$ ) for $\mathrm{C}_{49} \mathrm{H}_{72} \mathrm{~N}_{8} \mathrm{O}_{12}[\mathrm{M}+\mathrm{H}]^{+}$calc. 965.5343; found 965.5371.

3-endo-2-exo- $\mathrm{Di}\left[2^{\prime}\right.$-( $2^{\prime \prime}, 3^{\prime \prime}$-di-tert-butoxycarbonylguanidino)ethylcarbamoyl]-5,6-bis(4-fluorobenzyloxy)bicyclo[2.2.1] heptane (15f). Compound 15f was prepared from diacid $12 f(86 \mathrm{mg}, 0.20$ $\mathrm{mmol})$ and amine $14(181 \mathrm{mg}, 0.60 \mathrm{mmol})$ according to general procedure $\mathrm{D}$ and after purification by column chromatography (50-70\% EtOAc in pet. spirits) was isolated as a clear oil (90 mg, $45 \%) ; R_{\mathrm{f}}=0.13$ (50\% EtOAc in pet. spirits). ${ }^{1} \mathrm{H}$ NMR $(270 \mathrm{MHz}$, $\left.\mathrm{CDCl}_{3}\right) \delta 1.46-1.48(36 \mathrm{H}, \mathrm{m}, 4 \times t-\mathrm{Bu}), 1.62-1.66(1 \mathrm{H}, \mathrm{m}, \mathrm{H} 7 \mathrm{~s})$, $2.12(1 \mathrm{H}, \mathrm{d}, J=10.7 \mathrm{~Hz}, \mathrm{H} 7 \mathrm{a}), 2.46(1 \mathrm{H}, \mathrm{d}, J=7.3 \mathrm{~Hz}, \mathrm{H} 2), 2.60$ (1H, br s, H1), 2.72-2.75 (1H, m, H4), 2.83 (1H, app. t, $J=5.2 \mathrm{~Hz}$, H3), 3.28-3.60 (10H, m, $\left.4 \times \mathrm{CH}_{2}, \mathrm{H} 5, \mathrm{H} 6\right), 4.48-4.53(4 \mathrm{H}, \mathrm{m}, 2 \times$ $\left.\mathrm{CH}_{2} \mathrm{Ar}\right), 6.58(1 \mathrm{H}, \mathrm{t}, J=5.3 \mathrm{~Hz}, \mathrm{NH}), 6.92-7.00(4 \mathrm{H}, \mathrm{m}, \mathrm{ArH})$, 7.22-7.29 (4H, m, ArH), 8.07 (1H, t, $J=4.1 \mathrm{~Hz}, \mathrm{NH}), 8.47(1 \mathrm{H}, \mathrm{t}, J$ $=5.7 \mathrm{~Hz}, \mathrm{NH}), 8.70(1 \mathrm{H}, \mathrm{t}, J=5.9 \mathrm{~Hz}, \mathrm{NH}), 11.48(1 \mathrm{H}, \mathrm{s}, \mathrm{NH})$, $11.52(1 \mathrm{H}, \mathrm{s}, \mathrm{NH}) .{ }^{13} \mathrm{C} \mathrm{NMR}\left(67.5 \mathrm{MHz}, \mathrm{CDCl}_{3}\right) \delta 28.1,28.2,28.4$, 34.3, 39.4, 40.2, 40.4, 42.6, 43.8, 44.7, 45.2, 49.5, 71.6, 71.7, 78.6, 79.6, 80.2, 81.8, 83.4, 83.9, $115.0\left(\mathrm{~d},{ }^{2} J_{\mathrm{CF}}=18.4 \mathrm{~Hz}, 2 \times \mathrm{CH}\right)$, $115.3\left(\mathrm{~d},{ }^{2} J_{\mathrm{CF}}=18.5 \mathrm{~Hz}, 2 \times \mathrm{CH}\right), 129.5\left(\mathrm{~d},{ }^{3} J_{\mathrm{CF}}=9.8 \mathrm{~Hz}, 2 \times\right.$ $\mathrm{CH}), 129.7\left(\mathrm{~d},{ }^{3} J_{\mathrm{CF}}=9.9 \mathrm{~Hz}, 2 \times \mathrm{CH}\right), 134.4\left(\mathrm{~d},{ }^{4} J_{\mathrm{CF}}=3.2 \mathrm{~Hz}\right)$, $134.5\left(\mathrm{~d},{ }^{4} J_{\mathrm{CF}}=3.2 \mathrm{~Hz}\right), 162.3\left(\mathrm{~d},{ }^{1} J_{\mathrm{CF}}=243.7 \mathrm{~Hz}\right), 162.4\left(\mathrm{~d},{ }^{1} J_{\mathrm{CF}}=\right.$ $243.7 \mathrm{~Hz}), 153.2(2 \times \mathrm{C}), 156.8,158.1,163.1,163.6,172.3,174.4$. ${ }^{19} \mathrm{~F} \mathrm{NMR}\left(470 \mathrm{MHz}, \mathrm{CDCl}_{3}\right) \delta-115.17,-115.10$. HRMS (ESI, $\left.m / z\right)$ for $\mathrm{C}_{49} \mathrm{H}_{70} \mathrm{~F}_{2} \mathrm{~N}_{8} \mathrm{O}_{12}[\mathrm{M}+\mathrm{H}]^{+}$calc. 1001.5154; found 1001.5157. 
3-endo-2-exo-Di[ $2^{\prime}$-(2", $3^{\prime \prime}$-di-tert-butoxycarbonylguanidino)ethylcarbamoyl]-5,6-bis(3-bromobenzyloxy)bicyclo[2.2.1]heptane (15g). Compound $15 \mathrm{~g}$ was prepared from diacid $12 \mathrm{~g}$ (170 $\mathrm{mg}$, $0.31 \mathrm{mmol}$ ) and amine $14(280 \mathrm{mg}, 0.93 \mathrm{mmol})$ according to general procedure $\mathrm{D}$ and after purification by column chromatography (70\% EtOAc in pet. spirits) was isolated as a clear oil (185 mg, 53\%); $R_{\mathrm{f}}=0.32$ (70\% EtOAc in pet. spirits). ${ }^{1} \mathrm{H}$ NMR $\left(500 \mathrm{MHz}, \mathrm{CDCl}_{3}\right) \delta 1.46-1.49(36 \mathrm{H}, \mathrm{m}, 4 \times t-\mathrm{Bu}), 1.66(1 \mathrm{H}, \mathrm{d}, J=$ $10.4 \mathrm{~Hz}, \mathrm{H} 7 \mathrm{~s}), 2.12$ (1H, dd, $J=10.4,1.2 \mathrm{~Hz}, \mathrm{H7a}), 2.47$ (1H, d, $J=$ $5.9 \mathrm{~Hz}, \mathrm{H} 2), 2.61$ (1H, br s, H1), 2.78-2.79 (1H, m, H4), $2.85(1 \mathrm{H}$, $\mathrm{dd}, J=6.0,4.5 \mathrm{~Hz}, \mathrm{H} 3), 3.30-3.61\left(10 \mathrm{H}, \mathrm{m}, 4 \times \mathrm{CH}_{2}, \mathrm{H} 5, \mathrm{H} 6\right)$, 4.47-4.57 (4H, m, $\left.2 \times \mathrm{CH}_{2} \mathrm{Ar}\right), 6.59(1 \mathrm{H}, \mathrm{t}, J=5.6 \mathrm{~Hz}, \mathrm{NH}), 7.15-$ 7.18 (2H, m, ArH), 7.22-7.24 (2H, m, ArH), 7.37-7.39 (2H, m, ArH), 7.44-7.47 (2H, m, ArH), $8.11(1 \mathrm{H}, \mathrm{t}, J=4.0 \mathrm{~Hz}, \mathrm{NH}), 8.47$ $(1 \mathrm{H}, \mathrm{t}, J=5.5 \mathrm{~Hz}, \mathrm{NH}), 8.71(1 \mathrm{H}, \mathrm{t}, J=6.1 \mathrm{~Hz}, \mathrm{NH}), 11.47(1 \mathrm{H}, \mathrm{s}$, $\mathrm{NH}), 11.53(1 \mathrm{H}, \mathrm{s}, \mathrm{NH}) .{ }^{13} \mathrm{C}$ NMR $\left(125 \mathrm{MHz}, \mathrm{CDCl}_{3}\right) \delta 28.1,28.2$, 28.4, 34.3, 39.4, 40.3, 40.4, 42.5, 43.6, 44.8, 45.2, 49.4, 71.5, 71.7, 78.7, 79.6, 80.2, 82.1, 83.4, 83.9, 122.5, 122.6, 126.2, 126.3, 130.0, 130.1, 130.66, 130.68, 130.72, 130.75, 141.0, 141.1, $153.2(2 \times \mathrm{C})$, 156.9, 158.1, 163.1, 163.6, 172.2, 174.4. HRMS (ESI, $m / z$ ) for $\mathrm{C}_{49} \mathrm{H}_{70} \mathrm{Br}_{2} \mathrm{~N}_{8} \mathrm{O}_{12}[\mathrm{M}+\mathrm{H}]^{+}$calc. 1121.3553; found 1121.3541.

\section{General procedure E for Boc-removal of Boc-protected guanidines 15a-i}

To the stirring solution of Boc-protected guanidine (0.05 mmol) and $\mathrm{MeOH}(520 \mu \mathrm{L})$, was added dropwise $\mathrm{AcCl}$ (20 equiv.) and the reaction was stirred for $24 \mathrm{~h}$ at ambient temperature. The reaction mixture was concentrated under vacuum and the product was co-evaporated with $\mathrm{MeOH}(2 \times 0.5 \mathrm{~mL})$ to give the desired guanidinium $\mathrm{HCl}$ salt.

5,6-Bis(methoxy)bicyclo[2.2.1] heptane-3-endo-2-exo-dicarboxamidoethylguanidine hydrogen chloride (16a). Compound 16a was prepared from Boc-protected diguanidine 15a (42 mg, $0.05 \mathrm{mmol}$ ) according to general procedure $\mathrm{E}$ as a white solid (24 mg, 96\%); m.p: 161.5-195.0 ${ }^{\circ} \mathrm{C}$ (slow decomposition). ${ }^{1} \mathrm{H}$ NMR (270 MHz, CD $30 D) \delta 1.50(1 \mathrm{H}, \mathrm{d}, J=10.8 \mathrm{~Hz}, \mathrm{H} 7 \mathrm{a}), 1.80$ $(1 \mathrm{H}, \mathrm{d}, J=11.0 \mathrm{~Hz}, \mathrm{H} 7 \mathrm{~s}), 2.46(1 \mathrm{H}, \mathrm{br} \mathrm{s}, \mathrm{H} 2), 2.58-2.59(1 \mathrm{H}, \mathrm{m}$, H1), $2.65(1 \mathrm{H}, \mathrm{d}, J=5.3 \mathrm{~Hz}, \mathrm{H} 4), 3.17$ (1H, app. t, $J=4.5 \mathrm{~Hz}, \mathrm{H} 3)$, 3.33 (3H, s, OMe), 3.41 (3H, s, OMe), 3.35-3.43 (9H, m, $4 \times \mathrm{CH}_{2}$, H5), $3.51(1 \mathrm{H}, \mathrm{d}, J=6.3 \mathrm{~Hz}, \mathrm{H} 6), 8.22(1 \mathrm{H}, \mathrm{t}, J=4.5 \mathrm{~Hz}, \mathrm{NH}), 8.32$ $(1 \mathrm{H}, \mathrm{t}, J=4.6, \mathrm{NH}) .{ }^{13} \mathrm{C} \mathrm{NMR}\left(67.5 \mathrm{MHz}, \mathrm{CD}_{3} \mathrm{OD}\right) \delta 33.9,39.5$, 39.7, 42.0, 42.2, 45.4, 46.1, 47.6, 47.8, 58.8, 58.9, 81.8, 85.4, 158.9, 175.0, 176.7. HRMS (ESI, $m / z$ ) for $\mathrm{C}_{17} \mathrm{H}_{32} \mathrm{~N}_{8} \mathrm{O}_{4}[\mathrm{M}+2 \mathrm{H}]^{2+}$ calc. 207.1346; found 207.1341.

5,6-Bis(benzyloxy)bicyclo[2.2.1]heptane-3-endo-2-exo-dicarboxamidoethylguanidine hydrogen chloride (16). Compound 16b was prepared from Boc-protected diguanidine 15b (76 mg, $0.08 \mathrm{mmol}$ ) according to general procedure $\mathrm{E}$ as a white residue (47 mg, 96\%). ${ }^{1} \mathrm{H}$ NMR (500 MHz, $\left.\mathrm{CD}_{3} \mathrm{OD}\right) \delta 1.56(1 \mathrm{H}, \mathrm{d}, J=10.0$ Hz, H7a), 2.02 (1H, d, J=10.0 Hz, H7s), 2.53 (1H, br s, H2), 2.662.67 (2H, m, H1, H4), 3.18 (1H, app. t, $J=5.7 \mathrm{~Hz}, \mathrm{H} 3$ ), 3.21-3.39 $\left(8 \mathrm{H}, \mathrm{m}, 4 \times \mathrm{CH}_{2}\right), 3.62(1 \mathrm{H}, \mathrm{d}, J=5.3 \mathrm{~Hz}, \mathrm{H} 5), 3.73(1 \mathrm{H}, \mathrm{d}, J=5.5$ $\mathrm{Hz}, \mathrm{H} 6), 4.50-4.65$ (4H, m, $2 \times \mathrm{ArCH}_{2}$ ), 7.26-7.39 (10H, m, ArH). ${ }^{13} \mathrm{C}$ NMR (125 MHz, CD 3 OD) $\delta 34.3,39.6,39.7,41.97,42.01,46.4$ $(2 \times \mathrm{C}), 47.8,48.4,73.4,73.7,78.9,83.2,128.70,128.72,129.2(2$ $\times \mathrm{C}), 129.32(3 \times \mathrm{C}), 129.33(3 \times \mathrm{C}), 139.6,139.7,158.8,158.9$,
175.0, 176.7. HRMS (ESI, $m / z$ ) for $\mathrm{C}_{29} \mathrm{H}_{40} \mathrm{~N}_{8} \mathrm{O}_{4}[\mathrm{M}+2 \mathrm{H}]^{2+}$ calc. 283.1659; found 283.1667 .

5,6-Bis[(2-methylbenzyl)oxy] bicyclo[2.2.1]heptane-3-endo-2exo-dicarboxamidoethylguanidine hydrogen chloride (16c). Compound 16c was prepared from Boc-protected diguanidine 15c (54 mg, $0.05 \mathrm{mmol}$ ) according to general procedure $\mathrm{E}$ as a clear oil (8 mg, 24\%). ${ }^{1} \mathrm{H}$ NMR (500 MHz, CD 3 OD) $\delta 1.56(1 \mathrm{H}, \mathrm{d}, J$ $=10.3 \mathrm{~Hz}, \mathrm{H} 7 \mathrm{a}), 2.01$ (1H, d, $J=9.5 \mathrm{~Hz}, \mathrm{H} 7 \mathrm{~s}), 2.26$ (3H, s, ArMe), 2.30 (3H, s, ArMe), 2.53 (1H, br s, H2), 2.63-2.69 (2H, m, H1, $\mathrm{H} 4), 3.14-3.38$ (9H, m, $\left.4 \times \mathrm{CH}_{2}, \mathrm{H} 3\right), 3.64(1 \mathrm{H}, \mathrm{d}, J=5.1 \mathrm{~Hz}, \mathrm{H} 5)$, $3.76(1 \mathrm{H}, \mathrm{d}, J=5.5 \mathrm{~Hz}, \mathrm{H} 6), 4.49-4.67\left(4 \mathrm{H}, \mathrm{m}, 2 \times \mathrm{ArCH}_{2}\right), 7.08-$ 7.20 (7H, m, ArH), 7.29 (1H, d, $J=7.3 \mathrm{~Hz}, \mathrm{ArH}) .{ }^{13} \mathrm{C}$ NMR (125 $\left.\mathrm{MHz}, \mathrm{CD}_{3} \mathrm{OD}\right) \delta 19.07,19.09,34.4,39.6,39.7,41.98,42.04,46.2$, 46.3, 47.8, 48.4, 72.0, 72.1, 79.2, 83.6, 126.68, 126.73, 128.96, $128.99,130.2,130.3,131.1,131.2,137.4,137.6,138.1,138.2$, 158.86, 158.89, 175.1, 176.8. HRMS (ESI, $m / z$ ) for $\mathrm{C}_{31} \mathrm{H}_{44} \mathrm{~N}_{8} \mathrm{O}_{4}$ calc. $[\mathrm{M}+2 \mathrm{H}]^{2+}$ 297.1816; found 297.1820.

5,6-Bis[(4-trifluoromethylbenzyl)oxy] bicyclo[2.2.1]heptane3-endo-2-exo-dicarboxamidoethylguanidine hydrogen chloride (16d). Compound 16d was prepared from Boc-protected diguanidine 15d (87 mg, $0.08 \mathrm{mmol}$ ) according to general procedure $\mathrm{E}$ as a colourless sticky residue (40 mg, 66\%). ${ }^{1} \mathrm{H}$ NMR (500 MHz, CD $\left.{ }_{3} \mathrm{OD}\right) \delta 1.60(1 \mathrm{H}, \mathrm{d}, J=10.2 \mathrm{~Hz}, \mathrm{H} 7 \mathrm{~s}), 2.06$ $(1 \mathrm{H}, \mathrm{d}, J=9.9 \mathrm{~Hz}, \mathrm{H} 7 \mathrm{a}), 2.59(1 \mathrm{H}, \mathrm{br} \mathrm{s}, \mathrm{H} 2), 2.70-2.72(2 \mathrm{H}, \mathrm{m}$, $\mathrm{H} 1, \mathrm{H} 4), 3.21-3.38\left(9 \mathrm{H}, \mathrm{m}, 4 \times \mathrm{CH}_{2}, \mathrm{H} 3\right), 3.69(1 \mathrm{H}, \mathrm{d}, J=5.2 \mathrm{~Hz}$, H5), $3.80(1 \mathrm{H}, \mathrm{d}, J=5.5 \mathrm{~Hz}, \mathrm{H} 6), 4.63\left(2 \mathrm{H}, \mathrm{s}, \mathrm{ArCH}_{2}\right), 4.69-4.76$ $\left(2 \mathrm{H}, \mathrm{m}, \mathrm{ArCH}_{2}\right), 7.46-7.48$ (2H, m, ArH) , 7.51-7.52 (2H, m, ArH), 7.55-7.58 (4H, m, ArH). ${ }^{13} \mathrm{C}$ NMR (125 MHz, CD $\left.3 \mathrm{OD}\right) \delta 34.3$, 39.6, 39.7, 41.9, 42.0, 46.1, 46.2, 47.8, 48.4, 72.6, 72.7, 79.6, 83.6, $125.69\left(\mathrm{q},{ }^{1} J_{\mathrm{CF}}=269.7 \mathrm{~Hz}\right), 125.71\left(\mathrm{q},{ }^{1} J_{\mathrm{CF}}=269.7 \mathrm{~Hz}\right), 126.1(\mathrm{q}$, $\left.{ }^{3} J_{\mathrm{CF}}=3.4 \mathrm{~Hz}, 4 \times \mathrm{CH}\right), 129.2(4 \times \mathrm{C}), 130.58\left(\mathrm{q},{ }^{2} J_{\mathrm{CF}}=31.8 \mathrm{~Hz}\right)$, $130.60\left(\mathrm{q},{ }^{2} J_{\mathrm{CF}}=31.7 \mathrm{~Hz}\right), 144.46,144.54,158.83,158.85,174.9$, 176.6. ${ }^{19} \mathrm{~F}$ NMR $\left(470 \mathrm{MHz}, \mathrm{CD}_{3} \mathrm{OD}\right) \delta-65.41,-65.38$. HRMS (ESI, $m / z$ ) for $\mathrm{C}_{31} \mathrm{H}_{38} \mathrm{~F}_{6} \mathrm{~N}_{8} \mathrm{O}_{4}[\mathrm{M}+2 \mathrm{H}]^{2+}$ calc. 351.1533; found 351.1532 .

5,6-Bis[(3-fluorobenzyl)oxy] bicyclo[2.2.1]heptane-3-endo-2exo-dicarboxamidoethylguanidine hydrogen chloride (16e). Compound 16e was prepared from Boc-protected diguanidine 15e (72 $\mathrm{mg}, 0.07 \mathrm{mmol}$ ) according to general procedure $\mathrm{E}$ as a yellow solid (46 mg, 99\%); m.p: 77.4-82.4 ${ }^{\circ} \mathrm{C}$ (slow decomposition). ${ }^{1} \mathrm{H}$ NMR (500 MHz, CD $\left.3 \mathrm{OD}\right) \delta 1.58(1 \mathrm{H}, \mathrm{d}, J=10.2 \mathrm{~Hz}$, H7s), 2.02 (1H, d, $J=10.0 \mathrm{~Hz}, \mathrm{H} 7 \mathrm{a}), 2.57$ (1H, br s, H2), 2.682.69 (2H, m, H1, H4), 3.19-3.38 (9H, m, $\left.4 \times \mathrm{CH}_{2}, \mathrm{H} 3\right), 3.65(1 \mathrm{H}$, $\mathrm{d}, J=5.2 \mathrm{~Hz}, \mathrm{H} 5), 3.76(1 \mathrm{H}, \mathrm{d}, J=5.6 \mathrm{~Hz}, \mathrm{H} 6), 4.53-4.58(2 \mathrm{H}, \mathrm{m}$, $\left.\mathrm{ArCH}_{2}\right), 4.62-4.68$ (2H, m, $\left.\mathrm{ArCH}_{2}\right), 6.97-7.00$ (2H, m, ArH), 7.05 $(1 \mathrm{H}, \mathrm{d}, J=9.8 \mathrm{~Hz}, \mathrm{ArH}), 7.10-7.11(2 \mathrm{H}, \mathrm{m}, \mathrm{ArH}), 7.16(1 \mathrm{H}, \mathrm{d}, J=$ $7.6 \mathrm{~Hz}, \mathrm{ArH}), 7.28-7.34(2 \mathrm{H}, \mathrm{m}, \mathrm{ArH}) .{ }^{13} \mathrm{C} \mathrm{NMR}(125 \mathrm{MHz}$, $\left.\mathrm{CD}_{3} \mathrm{OD}\right) \delta 34.3,39.6,39.7,41.9,42.0,46.1(2 \times \mathrm{C}), 47.8,48.3$, $72.6,72.7,79.2,83.4,115.33\left(\mathrm{~d},{ }^{2} J_{\mathrm{CF}}=33.7 \mathrm{~Hz}\right), 115.26\left(\mathrm{~d},{ }^{2} J_{\mathrm{CF}}=\right.$ $26.6 \mathrm{~Hz}), 115.40\left(\mathrm{~d},{ }^{2} J_{\mathrm{CF}}=34.0 \mathrm{~Hz}\right), 115.43\left(\mathrm{~d},{ }^{2} J_{\mathrm{CF}}=27.0 \mathrm{~Hz}\right)$, $124.50\left(\mathrm{~d},{ }^{4} J_{\mathrm{CF}}=2.7 \mathrm{~Hz}\right), 124.52\left(\mathrm{~d},{ }^{4} J_{\mathrm{CF}}=2.6 \mathrm{~Hz}\right), 131.02\left(\mathrm{~d},{ }^{3} J_{\mathrm{CF}}\right.$ $=7.8 \mathrm{~Hz}), 131.08\left(\mathrm{~d},{ }^{3} J_{\mathrm{CF}}=6.6 \mathrm{~Hz}\right), 142.6\left(\mathrm{~d},{ }^{3} J_{\mathrm{CF}}=7.2 \mathrm{~Hz}\right)$, $142.8\left(\mathrm{~d},{ }^{3} J_{\mathrm{CF}}=7.1 \mathrm{~Hz}\right), 158.79,158.81,164.22\left(\mathrm{~d},{ }^{1} J_{\mathrm{CF}}=244.2\right.$ $\mathrm{Hz}), 164.23\left(\mathrm{~d},{ }^{1} J_{\mathrm{CF}}=242.8 \mathrm{~Hz}\right), 174.9,176.6 .{ }^{19} \mathrm{~F}$ NMR $(470$ $\mathrm{MHz}, \mathrm{CDCl}_{3}$ ) $\delta-116.03,-115.86$. HRMS (ESI, $m / z$ ) for $\mathrm{C}_{29} \mathrm{H}_{38} \mathrm{~F}_{2} \mathrm{~N}_{8} \mathrm{O}_{4}[\mathrm{M}+2 \mathrm{H}]^{2+}$ calc. 301.1565; found 301.1576. 
5,6-Bis[(4-fluorobenzyl)oxy] bicyclo[2.2.1] heptane-3-endo-2exo-dicarboxamidoethylguanidine hydrogen chloride (16f). Compound (16f) was prepared from Boc-protected diguanidine $15 \mathrm{f}(90 \mathrm{mg}, 0.09 \mathrm{mmol})$ according to general procedure $\mathrm{E}$ as a white solid (46 mg, 77\%); m.p: $94.0-110.0{ }^{\circ} \mathrm{C}$ (slow decomposition). ${ }^{1} \mathrm{H}$ NMR $\left(500 \mathrm{MHz}, \mathrm{CD}_{3} \mathrm{OD}\right) \delta 1.55(1 \mathrm{H}, \mathrm{d}, J=10.1 \mathrm{~Hz}$, H7a), $2.01(1 \mathrm{H}, \mathrm{d}, J=9.0 \mathrm{~Hz}, \mathrm{H} 7 \mathrm{~s}), 2.51(1 \mathrm{H}, \mathrm{br} \mathrm{s}, \mathrm{H} 2), 2.62(1 \mathrm{H}$, $\mathrm{m}, \mathrm{H} 1), 2.67(1 \mathrm{H}, \mathrm{d}, J=5.3 \mathrm{~Hz}, \mathrm{H} 4), 3.18-3.41\left(9 \mathrm{H}, \mathrm{m}, 4 \times \mathrm{CH}_{2}\right.$, H3), $3.63(1 \mathrm{H}, \mathrm{d}, J=5.8 \mathrm{~Hz}, \mathrm{H} 5), 3.73(1 \mathrm{H}, \mathrm{d}, J=5.5 \mathrm{~Hz}, \mathrm{H} 6)$, 4.47-4.53 (2H, m, $\left.\mathrm{ArCH}_{2}\right), 4.59\left(2 \mathrm{H}, \mathrm{s}, \mathrm{ArCH}_{2}\right), 7.00-7.05(4 \mathrm{H}, \mathrm{m}$, ArH), 7.29-7.31 (2H, m, ArH), 7.34-7.37 (2H, m, ArH). ${ }^{13} \mathrm{C} \mathrm{NMR}$ (125 MHz, $\left.\mathrm{CD}_{3} \mathrm{OD}\right) \delta 34.3,39.6,39.7,41.98,42.04,46.16,46.20$, $47.7,48.6,72.7,72.9,79.0,83.2,115.96\left(\mathrm{~d},{ }^{2} J_{\mathrm{CF}}=21.0 \mathrm{~Hz}\right)$, $115.97\left(\mathrm{~d},{ }^{2} J_{\mathrm{CF}}=21.6 \mathrm{~Hz}\right), 131.1\left(\mathrm{~d},{ }^{3} J_{\mathrm{CF}}=8.1 \mathrm{~Hz}, 4 \times \mathrm{CH}\right)$, $135.76\left(\mathrm{~d},{ }^{2} J_{\mathrm{CF}}=15.4 \mathrm{~Hz}\right), 135.78\left(\mathrm{~d},{ }^{2} J_{\mathrm{CF}}=15.6 \mathrm{~Hz}\right), 163.79(\mathrm{~d}$, $\left.{ }^{1} J_{\mathrm{CF}}=243.2 \mathrm{~Hz}\right), 163.81\left(\mathrm{~d},{ }^{1} J_{\mathrm{CF}}=242.9 \mathrm{~Hz}\right), 158.9(2 \times \mathrm{C})$, 175.0, 176.7. ${ }^{19} \mathrm{~F}$ NMR $\left(470 \mathrm{MHz}, \mathrm{CDCl}_{3}\right) \delta-118.04,-117.89$. HRMS (ESI, $m / z$ ) for $\mathrm{C}_{29} \mathrm{H}_{38} \mathrm{~F}_{2} \mathrm{~N}_{8} \mathrm{O}_{4}[\mathrm{M}+2 \mathrm{H}]^{2+}$ calc. 301.1565; found 301.1567 .

5,6-Bis[(3-bromobenzyl)oxy] bicyclo[2.2.1]heptane-3-endo-2exo-dicarboxamidoethylguanidine hydrogen chloride (16g). Compound $16 \mathrm{~g}$ was prepared from Boc-protected diguanidine $15 \mathrm{~g}$ (169 $\mathrm{mg}, 0.15 \mathrm{mmol}$ ) according to general procedure $\mathrm{E}$ as a white solid (115 mg, 97\%); m.p: 99.9-132.8 ${ }^{\circ} \mathrm{C}$ (slow decomposition). ${ }^{1} \mathrm{H}$ NMR $\left(500 \mathrm{MHz}, \mathrm{CD}_{3} \mathrm{OD}\right) \delta 1.57(1 \mathrm{H}, \mathrm{d}, J=10.5 \mathrm{~Hz}$, H7a), 2.01-2.04 (1H, m, H7s), $2.55(1 \mathrm{H}, \mathrm{br} \mathrm{s}, \mathrm{H} 2), 2.66-2.69(2 \mathrm{H}$, $\mathrm{m}, \mathrm{H} 1, \mathrm{H} 4), 3.19-3.40\left(9 \mathrm{H}, \mathrm{m}, 4 \times \mathrm{CH}_{2}, \mathrm{H} 3\right), 3.64(1 \mathrm{H}, \mathrm{d}, J=5.6$ $\mathrm{Hz}, \mathrm{H} 5), 3.75(1 \mathrm{H}, \mathrm{d}, J=5.3 \mathrm{~Hz}, \mathrm{H} 6), 4.50-4.56\left(2 \mathrm{H}, \mathrm{m}, \mathrm{ArCH}_{2}\right)$, 4.59-4.65 (2H, m, $\left.\mathrm{ArCH}_{2}\right), 7.21-7.27(3 \mathrm{H}, \mathrm{m}, \mathrm{ArH}), 7.32(1 \mathrm{H}, \mathrm{d}, J$ $=7.7 \mathrm{~Hz}, \mathrm{ArH}), 7.40-7.43(3 \mathrm{H}, \mathrm{m}, \mathrm{ArH}), 7.48(1 \mathrm{H}, \mathrm{m}, \mathrm{ArH}), 7.53$ $(1 \mathrm{H}, \mathrm{m}, \mathrm{ArH}) .{ }^{13} \mathrm{C}$ NMR $\left(125 \mathrm{MHz}, \mathrm{CD}_{3} \mathrm{OD}\right) \delta 34.3,39.6,39.7$, 41.96, 42.0, 46.13, 46.15, 47.7, 48.4, 72.6, 72.7, 79.3, 83.5, 123.32, 123.35, 127.59, 127.62, 131.16, 131.21, 131.66, 131.70, 131.8 (2 $\times$ C), 142.4, 142.5, 158.86, 158.87, 175.0, 176.7. HRMS (ESI, $m / z)$ for $\mathrm{C}_{29} \mathrm{H}_{38} \mathrm{Br}_{2} \mathrm{~N}_{8} \mathrm{O}_{4}[\mathrm{M}+2 \mathrm{H}]^{2+}$ calc. 361.0764; found 361.0774.

5,6-Bis[(4-bromobenzyl)oxy] bicyclo[2.2.1]heptane-3-endo-2exo-dicarboxamidoethylguanidine hydrogen chloride (16h). Compound 16h was prepared from Boc-protected diguanidine $15 \mathrm{~h}(57 \mathrm{mg}, 0.05 \mathrm{mmol})$ according to general procedure $\mathrm{E}$ as a clear oil (40 mg, 99\%). ${ }^{1} \mathrm{H}$ NMR $\left(500 \mathrm{MHz}, \mathrm{CD}_{3} \mathrm{OD}\right) \delta 1.56(1 \mathrm{H}, \mathrm{d}$, $J=10.2 \mathrm{~Hz}, \mathrm{H} 7 \mathrm{~s}), 2.00(1 \mathrm{H}, \mathrm{d}, J=9.9 \mathrm{~Hz}, \mathrm{H7a}), 2.53(1 \mathrm{H}, \mathrm{br} \mathrm{s}$, $\mathrm{H} 2), 2.64-2.67(2 \mathrm{H}, \mathrm{m}, \mathrm{H} 1, \mathrm{H} 4), 3.17-3.40\left(9 \mathrm{H}, \mathrm{m}, 4 \times \mathrm{CH}_{2}, \mathrm{H} 3\right)$, $3.61(1 \mathrm{H}, \mathrm{d}, J=5.6 \mathrm{~Hz}, \mathrm{H} 5), 3.73(1 \mathrm{H}, \mathrm{d}, J=5.6 \mathrm{~Hz}, \mathrm{H} 6), 4.46-$ $4.52\left(2 \mathrm{H}, \mathrm{m}, \mathrm{ArCH}_{2}\right), 4.56-4.62\left(2 \mathrm{H}, \mathrm{m}, \mathrm{ArCH}_{2}\right), 7.20-7.22(2 \mathrm{H}$, $\mathrm{m}, \mathrm{ArH}), 7.26-7.28(2 \mathrm{H}, \mathrm{m}, \mathrm{ArH}), 7.43-7.46(4 \mathrm{H}, \mathrm{m}, \mathrm{ArH}) .{ }^{13} \mathrm{C}$ NMR (125 MHz, $\left.\mathrm{CD}_{3} \mathrm{OD}\right) \delta 34.3,39.6,39.7,41.9,42.0,46.1,46.2$, 47.7, 48.4, 72.6, 72.8, 79.1, 83.3, 122.36, 122.40, $131.0(4 \times \mathrm{C})$, $132.40(2 \times \mathrm{C}), 132.41(2 \times \mathrm{C}), 139.0,139.1,158.81,158.84$, 174.9, 176.6. HRMS (ESI, $m / z$ ) for $\mathrm{C}_{29} \mathrm{H}_{38} \mathrm{Br}_{2} \mathrm{~N}_{8} \mathrm{O}_{4}[\mathrm{M}+2 \mathrm{H}]^{2+}$ calc. 361.0764; found 361.0769.

5,6-Bis(allyloxy) bicyclo[2.2.1]heptane-3-endo-2-exo-dicarboxamidoethylguanidine hydrogen chloride (16i). Compound 16i was prepared from Boc-protected diguanidine $15 \mathbf{i}(126 \mathrm{mg}$, $0.15 \mathrm{mmol}$ ) according to general procedure $\mathrm{E}$ as a yellow solid (24 mg, 31\%); m.p: 79.9-85.9 ${ }^{\circ} \mathrm{C} .{ }^{1} \mathrm{H}$ NMR $\left(500 \mathrm{MHz}, \mathrm{CD}_{3} \mathrm{OD}\right) \delta$ $1.52(1 \mathrm{H}, \mathrm{d}, J=10.3 \mathrm{~Hz}, \mathrm{H} 7 \mathrm{a}), 1.92(1 \mathrm{H}, \mathrm{d}, J=9.3 \mathrm{~Hz}, \mathrm{H} 7 \mathrm{~s}), 2.44$
(1H, br s, H2), $2.59(1 \mathrm{H}, \mathrm{d}, J=3.5 \mathrm{~Hz}, \mathrm{H} 1), 2.66(1 \mathrm{H}, \mathrm{d}, J=5.2$ $\mathrm{Hz}, \mathrm{H} 4), 3.16(1 \mathrm{H}$, app. $\mathrm{t}, J=5.1 \mathrm{~Hz}, \mathrm{H} 3), 3.30-3.46(8 \mathrm{H}, \mathrm{m}, 4 \times$ $\left.\mathrm{CH}_{2}\right), 3.57(1 \mathrm{H}, \mathrm{d}, J=6.0 \mathrm{~Hz}, \mathrm{H} 5), 3.63(1 \mathrm{H}, \mathrm{d}, J=5.4 \mathrm{~Hz}, \mathrm{H} 6)$, 4.00-4.09 (4H, m, $\left.2 \times \mathrm{CH}_{2} \mathrm{O}\right), 5.13-5.32\left(4 \mathrm{H}, \mathrm{m}, 2 \times \mathrm{CH}_{2} \mathrm{CH}\right)$, 5.86-5.98 $\left(2 \mathrm{H}, \mathrm{m}, 2 \times \mathrm{CH}_{2} \mathrm{CH}\right), 7.45-7.48(2 \mathrm{H}, \mathrm{m}, 2 \times \mathrm{NH}) .{ }^{13} \mathrm{C}$ NMR (125 MHz, $\left.\mathrm{CD}_{3} \mathrm{OD}\right) \delta 34.2,39.6,39.7,42.0,42.2,46.1,46.2$, 47.9, 48.4, 72.7, 72.8, 79.4, 83.3, 117.1, 117.2, $136.2(2 \times \mathrm{C})$, 158.87, 158.92, 175.0, 176.7. HRMS (ESI, $m / z$ ) for $\mathrm{C}_{21} \mathrm{H}_{36} \mathrm{~N}_{8} \mathrm{O}_{4}[\mathrm{M}$ $+2 \mathrm{H}]^{2+}$ calc. 233.1503; found 233.1502 .

\section{Crystallography}

Intensity data were collected with an CCD diffractometer using $\mathrm{Cu}-\mathrm{K} \alpha$ radiation, the temperature during data collection was maintained at 130.0(1) using an Oxford Cryosystems cooling device. The structure was solved by direct methods and difference Fourier synthesis. ${ }^{53}$ Thermal ellipsoid plots were generated using the program ORTEP-3 (ref. 54) integrated within the $\mathrm{WINGX}^{55}$ suite of programs. Disordered solvent, assumed to be ethanol was removed using the Squeeze procedure. ${ }^{56}$

\section{Disk diffusion - zone of inhibition assay}

A stock solution of $10 \mathrm{mg} \mathrm{mL}^{-1}$ was made for each compound under observation using DMSO as a solvent. Each of these stock solutions was then diluted by a factor of $1: 2$ to bring the concentration to $5 \mathrm{mg} \mathrm{mL}{ }^{-1}$. The diluted solutions were then filter-sterilized using a $0.2 \mu \mathrm{m}$ Nylon filter, and $10 \mu \mathrm{L}$ of the $5 \mathrm{mg} \mathrm{mL}^{-1}$ stock was pipetted onto a blank disk (i.e. $50 \mu \mathrm{g}$ per disk; Oxoid Limited, Hampshire, UK). All bacterial isolates were matched to a $0.5 \mathrm{McFarland}$ standard (in $0.9 \% \mathrm{NaCl}$ ) before they were swabbed onto nutrient agar. The controls used were a $10 \mu \mathrm{g}$ colistin disk (Oxoid), $10 \mu \mathrm{L}$ of DMSO and a plate swabbed with saline from the dispenser used.

\section{Minimum inhibitory concentration (MIC) determination}

Bacteria were obtained from American Type Culture Collection (ATCC; Manassas, VA, USA) as listed in Table S2 (see ESI†े). Bacteria were cultured in Nutrient broth (NB; Bacto Laboratories, catalog no. 234000) or Muller-Hinton broth (MHB; Bacto Laboratories, catalog no. 211443) at $37{ }^{\circ} \mathrm{C}$ overnight with shaking ( $\sim 180 \mathrm{RPM})$. A sample of each culture was diluted 50fold in fresh MHB and incubated at $37{ }^{\circ} \mathrm{C}$ for $1.5-3 \mathrm{~h}$ with shaking ( $180 \mathrm{RPM})$. Compound stock solutions were prepared as $10 \mathrm{mg} \mathrm{mL}^{-1}$ in DMSO and colistin was dissolved in Milli-Q water at $5.12 \mathrm{mg} \mathrm{mL}^{-1}$. The compounds, at twice the final desired concentration, were serially diluted 2 -fold across the wells of 96-well plates (Non-Binding Surface, Corning, catalog no. 3641). Mid-log phase bacterial cultures (after 1.5-3 h incubation) were diluted to a final concentration of $5 \times 10^{5}$ colony forming units (CFU) per $\mathrm{mL}$, and $50 \mu \mathrm{L}$ was added to each well giving a final compound concentration range of $32 \mu \mathrm{g} \mathrm{mL} \mathrm{m}^{-1}$ to $0.015 \mu \mathrm{g} \mathrm{mL} \mathrm{m}^{-1}$ (DMSO $\leq 1 \%$ ). MICs were determined visually after $20 \mathrm{~h}$ of incubation at $37^{\circ} \mathrm{C}$, with the MIC defined as the lowest compound concentration at which no bacterial growth was visible. 


\section{Cytotoxicity evaluation}

HEK293 (ATCC CRL-1573) and HepG2 (ATCC HB-8065) cells were seeded as 3000 cells per well in a 384-well plate in DMEM medium (GIBCO-Invitrogen \#11995-073), in which 10\% of FBS was added. Cells were incubated for $24 \mathrm{~h}$ at $37{ }^{\circ} \mathrm{C}, 5 \% \mathrm{CO}_{2}$ to allow cells to attach to the plates. A concentration series of compounds was then added into each well. The cells were incubated with the compounds for $24 \mathrm{~h}$ at $37{ }^{\circ} \mathrm{C}, 5 \% \mathrm{CO}_{2}$. After the incubation, $10 \mu \mathrm{M}$ resazurin (dissolved in PBS) was added to each well. The plates were then incubated for $2 \mathrm{~h}$ at $37{ }^{\circ} \mathrm{C}, 5 \%$ $\mathrm{CO}_{2}$. The fluorescence intensity was read using Polarstar Omega with excitation/emission 560/590. The data was analysed by Prism software. Results are presented as the average percentage of control $\pm \mathrm{SD}$ for each set of duplicate wells using the following equation:

$$
\begin{aligned}
\text { Percentage viability }= & \left(\text { FITEST }-\mathrm{FI}_{\text {Negative }} / \mathrm{FI}_{\text {UNTREATED }}\right. \\
& \left.-\mathrm{FI}_{\text {Negative }}\right) \times 100 .
\end{aligned}
$$

\section{Acknowledgements}

F.M.P., S.M.H. \& T.D.A. thank the ARC (DP140100227) and the Strategic Research Centre for Chemistry and Biotechnology (Deakin University) for financial support and a top-up scholarship for S.M.H. The authors would also like to thank Dr Damien Callahan for his assistance with the collection of HRMS and the Australian Research Council for funding Deakin University's Magnetic Resonance Facility through LIEF grant LE110100141. J.L. and R.L.N. are supported by a research grant from the National Institute of Allergy and Infectious Diseases of the National Institutes of Health (R01 AI098771). J.L. is an Australian NHMRC Senior Research Fellow. The content is solely the responsibility of the authors and does not necessarily represent the official views of the National Institute of Allergy and Infectious Diseases or the National Institutes of Health. The MIC screening was done in collaboration with CO-ADD (The Community for Open Access Drug Discovery) and we thank David L. Paterson (UQCCR) for his kind donation of clinical Gram-positive strains used for testing.

\section{References}

1 H. W. Boucher, G. H. Talbot, J. S. Bradley, J. E. Edwards, D. Gilbert, L. B. Rice, M. Scheld, B. Spellberg and J. Bartlett, Clin. Infect. Dis., 2009, 48, 1.

2 G. H. Talbot, J. Bradley, J. E. Edwards, D. Gilbert, M. Scheld and J. G. Bartlett, Clin. Infect. Dis., 2006, 42, 657-668.

3 M. A. Cooper and D. Shlaes, Nature, 2011, 472, 32.

4 M. S. Butler, M. A. Blaskovich and M. A. Cooper, J. Antibiot., 2013, 66, 571-591.

5 W. Yau, R. J. Owen, A. Poudyal, J. M. Bell, J. D. Turnidge, H. H. Yu, R. L. Nation and J. Li, J. Infect., 2009, 58, 138-144. 6 A. Aumelas, M. Mangoni, C. Roumestand, L. Chiche, E. Despaux, G. Grassy, B. Calas and A. Chavanieu, Eur. J. Biochem., 1996, 237, 575-583.
7 H. D. Thaker, F. Sgolastra, D. Clements, R. W. Scott and G. N. Tew, J. Med. Chem., 2011, 7, 2241-2254.

8 B. Ding, N. Yin, Y. Liu, J. Cardenas-Garcia, R. Evanson, T. Orsak, M. Fan, G. Turin and P. B. Savage, J. Am. Chem. Soc., 2004, 126, 13642-13648.

9 X. Chen, R. P. M. Dings, I. Nesmelova, S. Debbert, J. R. Haseman, J. Maxwell, T. R. Hoye and K. H. Mayo, J. Med. Chem., 2006, 49, 7754-7765.

10 M. Robertson, J. B. Bremner, J. Coates, J. Deadman, P. A. Keller, S. G. Pyne, K. Somphol and D. I. Rhodes, Eur. J. Med. Chem., 2011, 4201-4211.

11 R. P. Dings and K. H. Mayo, Acc. Chem. Res., 2007, 40, 10571065.

12 J. R. Pfister, L. Belardinelli, G. Lee, R. T. Lum, P. Milner, W. C. Stanley, J. Linden, S. P. Baker and G. Schreiner, J. Med. Chem., 1997, 40, 1773-1778.

13 P. J. Scammells, S. P. Baker, L. Bellardinelli, R. A. Olsson, R. A. Russell and S. A. Knevitt, Bioorg. Med. Chem. Lett., 1996, 6, 811-814.

14 D. M. J. Wright, S. P. Baker, S. G. Stewart and P. J. Scammells, Bioorg. Med. Chem. Lett., 1998, 8, 3647-3648.

15 S. A. Hutchinson, S. P. Baker and P. J. Scammells, Bioorg. Med. Chem., 2002, 10, 1115-1122.

16 L. C. Henderson, J. Li, R. L. Nation, T. Velkov and F. M. Pfeffer, Chem. Commun., 2010, 46, 3197-3199.

17 S. M. Hickey, S. K. Tripcony, R. Li, R. J. Williams and F. M. Pfeffer, Supramol. Chem., 2015, 27, 425-435.

18 A. J. Lowe and F. M. Pfeffer, Chem. Commun., 2008, 18711873.

19 F.-G. Klärner and T. Schrader, Acc. Chem. Res., 2012, 46, 967978.

20 A. J. Lowe, B. M. Long and F. M. Pfeffer, J. Org. Chem., 2012, 77, 8507-8517.

21 A. J. Lowe, B. M. Long and F. M. Pfeffer, Chem. Commun., 2013, 49, 3376-3388.

22 M. D. Johnstone, M. Frank, G. H. Clever and F. M. Pfeffer, Eur. J. Org. Chem., 2013, 5848-5853.

23 A. G. Martínez, E. T. Vilar, A. G. Fraile, S. de la Moya Cerero, P. Martínez Ruiz and C. Díaz Morillo, Tetrahedron: Asymmetry, 2007, 18, 742-749.

24 A. Lattanzi, P. Iannece, A. Vicinanza and A. Scettri, Chem. Commun., 2003, 1440-1441.

25 J. T. Derksen, J. D. Baldeschwieler and G. L. Scherphof, Proc. Natl. Acad. Sci. U. S. A., 1988, 85, 9768-9772.

$26 \mathrm{H}$. Cho, Y. Choi and J. Yhei, Derivatives of cyclic compound and the use thereof, WO2008/004788, 2008.

27 J. S. Bradshaw, K. E. Krakowiak, P. Huszthy and R. M. Izatt, J. Heterocycl. Chem., 1991, 28, 773-775.

28 G. Mehta and N. Mohal, Tetrahedron Lett., 1999, 40, 57915794.

29 G. Mehta, N. Mohal and S. Lakshminath, Tetrahedron Lett., 2000, 41, 3505-3508.

30 A. R. Hergueta, C. López, X. García-Mera and F. Fernández, Tetrahedron, 2004, 60, 10343-10352.

31 T. Purdie and J. C. Irvine, J. Chem. Soc., Trans., 1903, 83, 1021-1037. 
32 T. J. Gould, M. Balestra, M. D. Wittman, J. A. Gary, L. T. Rossano and J. Kallmerten, J. Org. Chem., 1987, 52, 3889-3901.

33 L. Van Hijfte, R. D. Little, J. L. Petersen and K. D. Moeller, J. Org. Chem., 1987, 52, 4647-4661.

34 R. E. Ireland, S. Thaisrivongs and P. H. Dussault, J. Am. Chem. Soc., 1988, 110, 5768-5779.

35 K. Mislow, J. Am. Chem. Soc., 1951, 73, 4043-4044.

36 A. Bouzide and G. Sauvé, Tetrahedron Lett., 1997, 38, 59455948.

37 M. Mousseron, R. Granger and A. Merle, Bull. Soc. Chim. Fr., 1947, 459-461.

38 H. G. Walker, M. Gee and R. M. McCready, J. Org. Chem., 1962, 27, 2100-2102.

39 M. Dejmek, H. Hrebabecky, M. Sala, M. Dracinsky and R. Nencka, Synthesis, 2011, 4077-4083.

40 S. Niwayama, H. Cho, M. Zabet-Moghaddam and B. R. Whittlesey, J. Org. Chem., 2010, 75, 3775-3780.

41 T. J. Donohoe, A. Jahanshahi, M. J. Tucker, F. L. Bhatti, I. A. Roslan, M. Kabeshov and G. Wrigley, Chem. Commun., 2011, 47, 5849-5851.

42 C. A. Grob, Angew. Chem., Int. Ed., 1969, 8, 535-546.
43 N. Sakai, T. Moriya and T. Konakahara, J. Org. Chem., 2007, 72, 5920-5922.

44 J. A. Marshall, B. M. Seletsky and G. P. Luke, J. Org. Chem., 1994, 59, 3413-3420.

45 G. D. Lander, J. Chem. Soc., Trans., 1903, 83, 414-423.

46 H. Finkelstein, Ber. Dtsch. Chem. Ges., 1910, 43, 1528-1532.

47 S. M. Hickey, T. D. Ashton, S. K. Khosa and F. M. Pfeffer, Synlett, 2012, 1779-1782.

48 S. M. Hickey, T. D. Ashton and F. M. Pfeffer, Asian J. Org. Chem., 2015, DOI: 10.1002/ajoc.201402242.

49 C. A. Lipinski, F. Lombardo, B. W. Dominy and P. J. Feeney, Adv. Drug Delivery Rev., 2012, 64, 4-17.

50 Z. G. Khalil, A. A. Salim, E. Lacey, A. Blumenthal and R. J. Capon, Org. Lett., 2014, 16, 5120-5123.

51 M. M. Flook, J. Börner, S. M. Kilyanek, L. C. H. Gerber and R. R. Schrock, Organometallics, 2012, 31, 6231-6243.

52 H. E. Gottlieb, V. Kotlyar and A. Nudelman, J. Org. Chem., 1997, 62, 7512-7515.

53 G. M. Sheldrick, Acta Crystallogr., 2007, 64, 112-122.

54 L. J. Farrugia, J. Appl. Crystallogr., 1997, 30, 565.

55 L. J. Farrugia, J. Appl. Crystallogr., 1999, 32, 837-838.

56 P. Van der Sluis and A. Spek, Acta Crystallogr., 1990, 46, 194201. 